No. $21-10$

\title{
High-Frequency Spending Responses to Government Transfer Payments
}

\section{Daniel H. Cooper and Giovanni P. Olivei}

\begin{abstract}
:
This paper evaluates the marginal propensity to consume (MPC) out of the 2020 fiscal stimulus payments using high-frequency, transaction-level data for a sample of low-income cardholders, many of whom are unbanked. Consumers' MPC out of non-stimulus income and their MPC out of tax refunds are estimated simultaneously. Spending responds less on impact to the stimulus payments than to non-stimulus income (15 cents versus 20 cents per dollar of income), but stimulus-payment spending quickly catches up and is noticeably higher than non-stimulus-income spending on a cumulative basis after 16 weeks (66 cents versus 46 cents). This finding is qualitatively quite robust, and there is relevant heterogeneity in the spending responses across cardholders that includes some pandemic-related effects.
\end{abstract}

JEL Classifications: E21

Keywords: consumption, fiscal stimulus payments, tax rebates, marginal propensity to consume

Daniel H. Cooper is a senior economist and policy advisor in the Federal Reserve Bank of Boston Research Department. His email is Daniel.Cooper@bos.frb.org. Giovanni P. Olivei is a senior vice president and the deputy director of the Research Department at the Federal Reserve Bank of Boston. His email is Giovanni.Olivei@bos.frb.org.

The authors thank Karen Dynan and Dhiren Patki for helpful suggestions, Ryan Wallace for comments as well as invaluable help processing the Facteus data, and Zorah Zafari and Hannah Rhodenhiser for research assistance.

The views expressed herein are those of the authors and do not indicate concurrence by the Federal Reserve Bank of Boston, the principals of the Board of Governors, or the Federal Reserve System.

This paper, which may be revised, is available on the website of the Federal Reserve Bank of Boston at https://www.bostonfed.org/publications/research-department-working-paper.aspx. 


\section{Introduction}

How consumption responds to temporary income shocks such as fiscal stimulus payments has been extensively researched and debated over time in the macroeconomics literature. Researchers continue to look for instances of economic windfalls to test the predictions of the permanent income hypothesis and see more broadly how consumer spending responds to various forms of income fluctuations. These studies, which recently have focused on the spending response to various government transfer payments and tax changes, have important implications for thinking about the efficacy and macroeconomic implications of fiscal policy designed to stimulate the economy during economic downturns.

This paper uses high-frequency, transaction-level payment-card data for a sample of lower-income, unbanked cardholders from Facteus to examine consumers' spending response to the 2020 fiscal stimulus payments that were distributed in the United States during the initial stages of the COVID-19 pandemic. Unlike the data used by previous papers in the literature, our data allow us to simultaneously control for cardholders' spending out of nonstimulus income and their spending out of tax refund payments. Our results show a relatively strong cumulative spending response to the stimulus payments compared with the spending responses to non-stimulus income and tax refund payments - a finding that is qualitatively quite robust. There is also relevant heterogeneity in the spending response across cardholders, some of which is related to the unique nature of the pandemic.

Even though the spending response to fiscal stimulus payments is well studied (for earlier literature, see, for example, Shapiro and Slemrod 2003, Johnson, Parker, and Souleles 2006, Agarwal, Liu, and Souleles 2007, Parker et al. 2013, Broda and Parker 2014, Shapiro and Slemrod 2009, Sahm, Shapiro, and Slemrod 2012), every economic downturn is different. The one associated with the pandemic was unique in that it originated from a public health shock rather than an economic one, resulting in government-mandated restrictions on economic activity, changes in individual behavior, and substantial fiscal support. Restrictions on activity, especially early in the pandemic when the Coronavirus Aid, Relief, and Economic Security (CARES) Act fiscal stimulus payments (EIP1) were disbursed, likely impacted individuals' ability, desire, and need to spend the stimulus monies - a reality highlighted in Coibion, Gorodnichenko, and Weber (2020) when discussing survey data results

on consumers' reported and planned spending response to the EIP1 payments. Studying the spending response to the EIP1 payments is therefore relevant for understanding the benefits of fiscal stimulus in response to a nontraditional economic downturn. 
The transaction-level data we employ from Facteus' US Consumer Payments data panel provide us with a useful perspective into consumers' spending response to the EIP1 payments. While the data are not representative of the US population, they cover a segment (lower-income and unbanked/underbanked) that at least a priori was more likely to receive and need the stimulus monies (and other benefits) provided by the CARES Act. Several additional factors also make our data set relevant for studying consumers' marginal propensity to consume (MPC) out of the EIP1 payment. First, the data are high frequency and include spending transactions and deposits other than the stimulus payments for a given card, whereas many previous studies on tax rebates lack information on individuals' nonstimulus income. Second, the data set is a panel, and we can include cardholder-spending and deposit data prior to the pandemic to help better identify the relationship between expenditures and different sources of income. Third, we are able to isolate EIP1 payments from other forms of government deposits, including tax refunds. This allows us to compare how cardholders' spending responds to the fiscal stimulus payments relative to other large, onetime government deposits. Fourth, we can analyze potential heterogeneity in the spending response across cards based on several factors including 2019 income, expenditure type, and whether a cardholder was unemployed (receiving unemployment insurance benefits) at some point during the pandemic as well as pandemic-related factors such as public health-related restrictions (which varied across locations) that might have limited cardholders' ability and willingness to spend.

We find a relatively strong spending response to the EIP1 payment, with expenditures increasing 15 cents per dollar in the week the payment was received before rising over time and reaching about 66 cents per dollar cumulatively after 16 weeks. In comparison, the MPC out of non-stimlulus (non-refund) income (incomeX) is somewhat larger on impact (20 cents) but smaller cumulatively (46 cents). That is, the spending response to the EIP1 payment was slower initially than for other temporary income fluctuations, but became larger over time - consistent with there being constraints on economic activity around the time the vast majority of stimulus funds were disbursed. We further find that the cumulative MPC out of tax refunds is similar to that of incomeX after 16 weeks.

Overall, our estimated spending response to the EIP1 payment is relatively large. Although the low-income cardholders in our sample do not appear to have spent all of their stimulus funds, we find stronger stimulus responses for cardholders with particularly low 2019 income (bottom quartile of cardholders in our sample) and for cardholders who received unemployment insurance (UI) benefits during the pandemic. While unemployed individuals 
typically have a greater need than others for income to finance expenditures, the latter result is interesting given the generosity of UI benefits during the pandemic and could reflect the timing of the stimulus receipt relative to UI benefit disbursement or the general need of these cardholders despite the size of the benefits. ${ }^{1}$ There is also evidence that the nature of the pandemic impacted cardholders' spending response, especially in terms of the types of goods and services they purchased.

The cumulative EIP1 effects we find are somewhat larger than those in the recent literature, although we study the effects over a longer time horizon. In particular, Baker et al. (2020) and Karger and Rajan (2021) use daily transaction-level data and evaluate the impact of the EIP1 payments in a fairly narrow window around their receipt. Baker et al. (2020) find that spending increased 25 to 40 cents per dollar of stimulus within the first week, and individuals with low account balances spent more than 40 percent of their stimulus payment within the first month. Karger and Rajan (2021) use daily transaction data from Facteus for a sample of cardholders who did or did not receive an EIP1 payment between April 10 and April 15, 2020. ${ }^{2}$ Focusing on a two-week window around the EIP1 payment receipt, they find that, overall, consumers spent about 48 percent of the stimulus payments, with the actual amounts varying somewhat based on the EIP1 amount. ${ }^{3}$

Other related papers include Coibion, Gorodnichenko, and Weber (2020), which, using survey data (Nielsen Homescan survey), finds that a fairly representative group of US households spent around 40 percent of the stimulus funds - an amount that is lower than what we find in our low-income sample. The authors further document heterogeneous responses based on households' demographic and financial characteristics. Cox et al. (2020) do not examine the consumption response to the stimulus payments directly, but show that spending growth rebounded faster starting in mid-April 2020 (after the initial pandemic-related economic shutdowns) for low-income households - a pattern that coincides with the timing of the EIP1 payments and expanded UI benefits from the CARES Act. Finally, while not

\footnotetext{
${ }^{1}$ Early on in the pandemic, state UI systems were overwhelmed with the volume of claims, and so many payments were delayed.

${ }^{2}$ Karger and Rajan (2021) use a one-time data snapshot from Facteus, whereas our sample is broader and built on an (ongoing) daily data feed.

${ }^{3}$ The sample Karger and Rajan (2021) use excludes cardholders who received non-stimulus income during their estimation window, and they evaluate the effects of the stimulus payments using a difference-indifferences approach. In comparison, we focus on all cardholders who we identify as having received an EIP1 payment in 2020 and trace how their spending evolved over many weeks in response to the payment and compared with how it evolved in response to non-stimulus income.
} 
focused on the pandemic, Baugh et al. (2021) consider how taxpayers adjust (smooth) their consumption in response to tax payments or tax refunds using transaction-level data from an online account aggregator. Using a higher (more representative) income sample than ours, they find that individuals consume about 8 percent of their tax refund in the month it is received and about 15 percent over the following three months - an effect that is a considerably smaller than what we find.

Most previous studies avoid controlling for non-stimulus income by appealing to the fact that the disbursement of a certain tax rebate is random or otherwise uncorrelated with individual income, which allows the authors to estimate an unbiased MPC out of the stimulus funds. ${ }^{4}$ In comparison, we have a panel of low-income cardholders, and even if the stimulus was widely distributed during the early stages of the pandemic, it may not have been orthogonal to other sources of income for these cardholders. In particular, the pandemic disproportionately impacted low-income workers, especially early on, which may have resulted in cardholders' experiencing job and earnings losses at the same time as the stimulus payments were sent out. Controlling for non-stimulus income is therefore important for helping to pin down the stimulus effect. The MPC estimates out of non-stimulus income and out of tax rebates also provide context for judging whether our observed stimulus response is large or small compared with spending responses to other temporary income changes.

The remainder of this paper proceeds as follows. Section 2.2 discusses our data and empirical framework including how we identify different types of income in our data set. Section 3 presents our baseline results and extensions. Section 4 discusses the literature on the spending effects of earlier tax rebates, and Section 5 concludes.

\section{Empirical Setup and Data}

\subsection{Empirical Specification}

While we have daily transaction-level data, we conduct our empirical analysis at a weekly frequency to limit noise. We use the following empirical model for that analysis: ${ }^{5}$

\footnotetext{
${ }^{4}$ Many of the data sets used in previous studies lack sufficient data on non-stimulus income.

${ }^{5}$ We explain this timing choice further in section 2.3 when we discuss our data sample.
} 


$$
\begin{aligned}
C_{t}^{i}= & \beta_{0}^{Y} Y_{t}^{i}+\beta_{0}^{S} S T I M_{t}^{i}+\beta_{0}^{R} R E B_{t}^{i}+\sum_{k=1}^{J} \beta_{k}^{Y} Y_{t-k}^{i}+\sum_{k=1}^{J} \beta_{k}^{S} S T I M_{t-k}^{i} \\
& +\sum_{k=1}^{J} \beta_{k}^{R} R E B_{t-k}^{i}+\delta_{t}+\gamma^{i}+g^{j}+w^{k}+g^{j} \cdot \delta_{t}+\epsilon_{t}^{i},
\end{aligned}
$$

where $C_{t}^{i}$ is spending on card $i$ during week $t ; Y_{t}^{i}$ is (after-tax) income exclusive of stimulus payments and federal tax rebates (incomeX) on card $i$ during week $t$; STI $M_{t}^{i}$ is the stimulus payment amount, if any, during the week; and $R E B_{t}^{i}$ is any tax refund amount received during the week. We also include up to $J$ weekly lags of incomeX, stimulus amounts, and federal tax rebate amounts. In our baseline specification, $J=16$ - the equivalent of four months. ${ }^{6}$ The specification also includes a series of fixed effects to control for both common and card-specific factors that may impact weekly spending and the estimated MPC out of any of the various income measures. In particular, our specification includes time (date) fixed effects $\left(\delta_{t}\right)$, card fixed effects $\left(\gamma^{i}\right)$, location fixed effects based on the county in which the cardholder resides $\left(g^{j}\right)$, week-of-the-year effects $\left(w^{k}\right)$, and location-specific time effects $\left(g^{j} \cdot \delta_{t}\right)$. This last control captures common effects in a certain area that may impact a cardholder's ability (or desire) to spend, especially during the pandemic, while the week-ofthe-year effects account for spending being generally higher (lower) in certain weeks of the year, such as around Thanksgiving and Christmas. ${ }^{7}$

Our main focus in Equation 1 is the estimated MPC out of the stimulus payment, both on impact $\beta_{0}^{S}$ and cumulatively over time $\sum_{k=0}^{J} \beta_{k}^{S}$ for $k \leq J$. (We considered allowing for anticipatory spending effects for stimulus or non-stimulus income when estimating Equation 1 but found that they were nonexistent, and therefore, for simplicity we do not include them.) We are further interested in how the MPC out of stimulus income compares with the MPC out of incomeX $\sum_{k=0}^{J} \beta_{k}^{Y}$ as well as the MPC out of tax rebates $\sum_{k=0}^{J} \beta_{k}^{R}$. Given that our specification includes cardholder fixed effects, these MPC estimates capture cardholders' spending response to temporary income changes - deviations in income receipts from average (or permanent) income.

\footnotetext{
${ }^{6}$ Standard information criterion tests (AIC/BIC) call for a long lag structure (not shown). Results using only 12 lags (or three months) are similar.

${ }^{7}$ We also considered week-by-location fixed effects to account for the fact that tax holidays and back-toschool shopping occur at different times in different locations. These additional controls had little effect on our results.
} 


\subsection{Facteus Data}

\section{Overview}

Our analysis uses transaction-level data from Facteus' US Consumer Payments data panel, which tracts spending and deposits from a panel of debit cards, alternative debit cards, and credit cards. ${ }^{8}$ The panel comprises more than 20 million active cards, and the anonymized data we receive are highly detailed and track daily income and spending transactions across four specific card types: general purpose cards, payroll cards, (traditional) debit cards, and government cards. The vast majority of cards in our sample (and in the panel) are payroll and general purpose cards. ${ }^{9}$ According to Facteus, cardholders in the panel are lower-income individuals who use these prepaid-type cards rather than a traditional bank account. The data also include members of the millennial generation, who collectively conduct much of their banking online and who utilize so-called challenger banks to manage their finances.

The data include a field (ARM_TXN_CDE) that allows us to distinguish between credit (income) and debit (spending) transactions along with merchant credits. The spending transactions are also tagged with a merchant category code (MCC), a universal classification system designed to identify the type of merchant with which a transaction occurs. For much of our analysis we aggregate all spending data, however, we use the MCC data to assign spending to various broad categories for some of our analysis in section ??. A beneficial feature of the Facteus data is that they enable simultaneous observation of cardholders' spending and income. ${ }^{10}$ Importantly, the data also contain an electronic signature field (MRCHNT_NME) that enables us to determine the source of cardholders' income receipts. As we discuss further below, this field is highly detailed and allows us to distinguish stimulus payments from tax refunds, unemployment insurance (UI) benefits, and more general sources of cardholder income.

A potential shortcoming of the Facteus data is that they are card-level rather than

\footnotetext{
${ }^{8}$ Facteus partners directly with financial institutions, payment processors, and fintechs to source the transaction data. The data are processed through Facteus' synthetic data process to eliminate all personally identifiable information (PII) while maintaining statistical accuracy of the transaction information and complying with data privacy regulations. Facteus also infuses random noise into the transaction amounts to further preserve confidentiality. To learn more about the data, visit www.facteus.com or contact steve.shaw@facteus.com.

${ }^{9}$ See Figure A.2 for more detailed descriptions of these card types.

${ }^{10}$ Much of the existing literature on tax rebates utilizes data with detailed expenditure information but limited, if any, data on individuals' non-stimulus income.
} 
person-level, and we do not know whether a cardholder has multiple cards in the data set or whether they have external accounts or otherwise engage in (electronic) transactions outside the panel. ${ }^{11}$ However, we have been told by our contacts at Facteus that given the demographics of the panel, most cardholders are unbanked and do not have more than one card. It is worth noting that bank account-based transaction-level data, like those used in Cox et al. (2020), while potentially providing a somewhat more comprehensive picture of an individual's spending and income, also suffer from similar limitations, since individuals may, for instance, have bank accounts at other institutions. In fact, higher-income individuals are perhaps more likely to have accounts at multiple institutions.

While the Facteus data are also not representative of the US population, we observe income and spending behavior for a group of low-income people, who are likely to have a need for the stimulus monies they receive. Therefore, we view the data as relevant for studying the impact of the EIP1 payments on consumption and believe more generally that the advantages of the Facteus data for our analysis outweigh the limitations. We discuss the data, including our cleaning and classification procedures, in more detail in the Appendix.

\section{Identifying Different Sources of Income}

While card-level spending is relatively easy to categorize due to the MCC codes associated with each transaction, differentiating between stimulus payments, tax refunds, and other types of deposits requires gleaning relevant descriptors from the MRCHNT_NME field associated with each transaction. Using this information, we categorize deposits as stimulus payments, federal tax refunds, other US Treasury payments, state tax refunds, unemployment insurance (UI) benefits, and "all other," which includes payroll and other deposits.

Specifically, we use regular expression searches (REGEX) to parse the electronic (MRCHNT_NME) signatures for known (or discovered) descriptors associated with different payment types. As an example, federal tax refunds are often associated with an electronic signature such as "IRS TREAS 310 TAX REF," while many fiscal stimulus payments have a signature of "IRS TREAS 310 TAXEIP." We verified these and other signatures - also referred to as strings - associated with tax refunds and stimulus payments through a variety of web searches. Since tax refunds and stimulus payments arrived at similar times in 2020, we are careful in distinguishing between the two. Also, states have known strings associated

\footnotetext{
${ }^{11}$ We do observe ATM withdrawals, but not what the cash is used for. Based on the assumption that cardholders spend all of the cash they withdraw, we include ATM withdrawal amounts in our measure of total spending. Our results are very similar, though, if we exclude these transactions.
} 
with their UI benefit deposits, such as "NYS DOL UI DD" for New York, and we use this information to identify UI benefit receipts. ${ }^{12}$

In addition, sometimes the electronic signature associated with an IRS/Treasury deposit includes only generic information such as "IRS TREAS 310." There are also transactions labeled "IRS TREAS 310 TAX REF" with timing and amounts that are consistent with a stimulus payment. We identify such a deposit as an EIP1 payment only if it occurred after April 10, 2020, when the EIP1 payments began, and the amount is consistent with the common payout amounts. All other deposits with generic US Treasury signatures are assigned to the other federal transfer payment category unless there is a clear indicator that it is a tax refund payment. We are quite confident that our REGEX approaches, which we describe in further detail in the Appendix, limit potential false positives, especially for fiscal stimulus payments.

Our main analysis divides income into three sources based on our REGEX categorization: stimulus payments, federal tax refunds, and all other deposits (incomeX), which include all other state and federal transfer payments. ${ }^{13}$ IncomeX should be a mostly after-tax income measure to the extent that payroll deposits and other benefit deposits, such as UI, are net of tax withholding. In addition, we separate federal tax rebates from other cardholder income given recent work by Baugh et al. (2021) on the spending response to such transfer payments. Estimating how cardholders' spending responds to tax refunds, which are an alternative type of one-time payment, provides a reference point for comparing our estimated MPC out of the EIP1 payments.

\subsection{Analysis Sample}

The Facteus data begin in 2012, with the sample becoming better populated across card types around 2014. Given that most of the cards in the data set are general purpose or payroll cards - effectively prepaid cards that are not tied to bank accounts - they tend to be in the sample for only a few years. In addition, while the data are daily, with multiple transactions possible within a day, not all cards transact regularly, even at a weekly frequency, and cards that do transact frequently may have infrequent deposits given the weekly, biweekly, bimonthly, or monthly frequency of many employers' payroll systems. Since our baseline

\footnotetext{
${ }^{12}$ The electronic signatures associated with UI benefits by state can be found here: https://www.neach. org/Solutions/COVID-19-Information/Unemployment-Payments.

${ }^{13}$ IncomeX also potentially includes state tax refunds, which tend to be small and not easily identifiable with REGEX searches for all states.
} 
specification includes numerous lags of income, stimulus payments, and tax refund payments to trace cardholders' spending response over time, a goal of our sample selection criteria is to generate a sample of cards with well-populated weekly transaction data.

We construct our estimation sample by first pulling all the transactions associated with cards that we identify as having received an EIP1 payment. We restrict our analysis to cards with EIP1 payments because we include data from all of 2020 (and 2019) in our sample, and if a card does not have an observed EIP1 payment, we cannot determine whether the cardholder did not receive one or received one that we do not observe in our data. ${ }^{14}$ In addition, given that we are not employing a difference-in-differences estimation approach, including only cards that we know received EIP1 payments will help us to compare broadly similar cards and isolate the stimulus effect, conditional on receipt of the payment, while controlling for other forms of income.

Our estimation period begins the week ending January 6, 2019, and concludes the week ending December 27, 2020, to avoid stimulus payments from the second round (EIP2), which were deposited in consumers' accounts as early as December 28, 2020. Given the lag structure of our empirical setup, we include only cards that received an EIP1 payment before September 14, 2020. ${ }^{15}$ We further restrict our sample to cards that were active (had at least one credit or debit transaction) for 100 or more weeks combined in 2019 and 2020. This ensures a roughly balanced sample in which our results are not dominated by cards that were active only during the pandemic or cards that had infrequent and potentially large spending transactions only when they received deposits. The balanced panel also ensures that we have an adequate number of observations prior to the pandemic to help better identify the relationship between spending and incomeX for each card. ${ }^{16}$

To further avoid infrequently used or atypical cards from unduly influencing our results, we also require that cards had deposits (income) of $\$ 1,000$ or more in 2019 and 2020 and at least 10 deposits and 100 spending transactions over our sample period (buying a coffee at Starbucks, for example, is one transaction). We also drop cards that appear to be outliers

\footnotetext{
${ }^{14}$ We have confidence in our REGEX approach to identifying EIP1 payments, however, we may not capture every payment, and importantly, the EIP1 payments for some cardholders may have been sent via check or via (separate) prepaid debit cards.

${ }^{15}$ While we observe the vast majority of EIP1 payments in April and May 2020 - consistent with when they were sent by the Treasury department - some individuals received payments later in the year, and we chose a September cutoff to ensure that all 16 lags of the stimulus payments are populated for each card.

${ }^{16}$ Our results are similar, as we discuss later, if we relax the balanced panel restriction and require cards to have been in the sample for only 50 or more weeks over our two-year sample period.
} 
in terms of having excessively high numbers of transactions. ${ }^{17}$ To further limit the effects of outliers, we winsorize weekly consumption and weekly incomeX at the 1st and 99th percentiles of their respective distributions. Cards must also have valid geographic information (Zip code where the cardholder resides) so that we can control for local trends and other effects that could have impacted cardholders' income and spending. In addition, we drop cards for which we observe multiple EIP1 payments, since we do not know the reason for these multiple payments and worry they could reflect something inherently different about the cardholders. ${ }^{18}$

Similar to Baugh et al. (2021), we also drop cards with large observed tax refunds in either 2019 or $2020{ }^{19}$ We further require that cards had at least one tax refund in 2019 or 2020 that was $\$ 100$ or more. Again, we believe this approach allows us to best compare the spending response to stimulus payments, incomeX, and tax refunds across cards that are broadly similar. If cards did not have a tax refund in 2019 or 2020, we cannot determine whether the cardholders are inherently different from the cardholders who did receive a tax refund in addition to a stimulus payment. Indeed, it may be the case that active cards with stimulus payments and tax refunds are more likely to serve as the primary (or only) account through which the cardholder conducts financial transactions. ${ }^{20}$

Finally, we include only the first round of stimulus payments associated with the pandemic in our sample and analysis. The EIP1 payments were disbursed at a time of great need and high uncertainty in the US economy (and the world economy). Understanding how people responded to the payments - especially a sample of low-income individuals who

\footnotetext{
${ }^{17}$ Specifically, we drop cards in roughly the top 1 percent of the transaction distribution —ones with more than 250 deposits or more than 2,750 spending transactions over the course of 2019 and 2020. Our results are qualitatively quite similar if we relax these restrictions.

${ }^{18}$ There is a limited number of cards with multiple EIP1 transactions that meet our baseline sample criteria, and our results are robust to including these cards in the analysis. We do not believe that finding cards with multiple EIP1 payments reflects a flaw in our process for identifying stimulus payments. Representatives from Facteus said that they report only posted and not pending transactions, so it is not a question of, for example, the IRS trying to post a payment and having it not go through. The multiple payments also have distinct dates and payment strings, as show in the example in Table A.1 in the Appendix. It is also possible that two different family members received payments on the same card that arrived at different times.

${ }^{19}$ We require that refunds were $\$ 5,000$ or less compared with the cutoff in Baugh et al. (2021) of $\$ 10,000$. However, the income level of our sample of cardholders is much lower than that of their sample (average cardholder income of $\$ 24,338$ in our sample compared with $\$ 68,543$ in theirs), so a cutoff of $\$ 5,000$ seems more appropriate (and conservative).
}

${ }^{20}$ Our findings are robust to relaxing these sample restrictions, as we discuss further in section 3.2. 
had a particular need for the funds - is important for thinking about the effectiveness of such stimulus during periods of extreme economic stress and uncertainty. The spending responses to the second (EIP2) and third (EIP3) stimulus payments are also relevant, and we plan to study them and compare the spending responses across all three payments in follow-up work to this paper. The EIP2 and EIP3 payments were undoubtedly needed by certain individuals - especially the EIP2 payment after some supplemental UI benefits had lapsed-but they occurred at a time of greater economic clarity, as consumers and firms had adjusted to the pandemic even if the evolution of the virus and public health situation remained unclear.

\subsection{Sample Statistics}

Our baseline sample includes 6,940 unique cards and more than 625,000 total weekly observations. Roughly 90 percent of the cards are so-called payroll cards, and the remainder are general purpose cards. If we relax the restrictions that all cards must have had at least one tax refund of $\$ 100$ or more, as we do in some of our robustness analysis, the sample includes 11,959 unique cards and more than 1.07 million observations. Returning to our baseline sample, the geographic distribution of cards across states is relatively consistent with the US population share for each state, as shown in the Appendix (see Figure A.1). The share of cards in some large, wealthier states such as California, Florida, and New York is lower than the overall population shares for those states, while less affluent states in Appalachia and the Midwest such as Kentucky, Tennessee, Indiana, and Ohio are somewhat overrepresentedpatterns that are broadly consistent with the Facteus data capturing lower-income, often unbanked cardholders.

Table 1 reports summary statistics for our sample of cards. Mean and median total income in 2019 was about $\$ 28,118$ and $\$ 24,337$, respectively, ${ }^{21}$ with both measures well below 2019 per capita disposable personal income in the United States $(\$ 49,763)$ and 2019 median household income $(\$ 68,703)$. These income statistics confirm that we have a relatively low-income sample of cardholders. Mean total income and median total income in 2020 were somewhat higher than in 2019 likely due at least in part to the generosity of transfer payments during the pandemic (EIP1 payments plus supplemental $\$ 600$-a-week unemployment benefits). Mean incomeX and median incomeX were lower than total income, but they were similarly higher in 2020 than in 2019. Even excluding the stimulus payments, it is not

\footnotetext{
${ }^{21}$ Total income equals all deposits onto a card in a given year.
} 
surprising that cardholders' income in 2020 was greater than in 2019 given the generosity of UI benefits (\$600-a-week supplemental payments), increases in the minimum wage, and the greater use of electronic payment methods during the pandemic. Indeed, the median number of deposits onto cards in 2020 was about 9 percent larger in 2020 than in 2019, and the number of spending transactions was also larger.

Average weekly spending was about $\$ 312$, while average weekly incomeX was about $\$ 463$, suggesting that cardholders on average did not spend all of the non-stimulus, non-tax refund monies they received. Indeed, average weekly consumption relative to income (CY) in 2019 and 2020 was around 0.70 . This average spending rate out of income seems low; however, the spending rate rises as income in our sample declines. In particular, cards with $\$ 15,000$ or less total income in 2019 had an average CY of about 0.81, while average CY for cards with 2019 income of $\$ 10,000$ or less was about 0.91 . We discuss the seemingly low spending rate further, along with the implications for our analysis, in the next subsection.

In addition, the median (and minimum) EIP1 payment was $\$ 1,200$, while the mean was greater, consistent with the benefit structure of the first round of stimulus payments. ${ }^{22}$ The average tax refund amounts in 2019 and 2020 were similar in magnitude to the average EIP1 payments, but the median tax refund amounts in both years were somewhat smaller, with refund payments exhibiting greater variance than stimulus payments, consistent with the fact that EIP1 payments were the same across a fairly wide (2019) income range, whereas the tax system is progressive and refund amounts depend on individual-specific tax liabilities and payments. Finally, the mean age of cardholders in our sample is 39 years old, while the median is about 36-suggesting that we have a somewhat younger sample of cardholders compared with the United States as a whole. ${ }^{23}$

\subsection{Observed Spending Rates out of Income}

The roughly 70 percent average spending rate in our sample of relatively low-income cardholders is below the spending rate observed for individuals with similar income in frequently

\footnotetext{
${ }^{22}$ Facteus infuses noise in the deposit and spending amounts data, so we will not observe a stimulus payment that is exactly $\$ 1,200$ or $\$ 1,700$. Our REGEX procedure for identifying these payments accounts for this noise. (Some cardholders likely are married or have dependents.)

${ }^{23}$ The median age of the US population in 2020 (individuals age 18 or older) was 47 , and the mean was 47.8 based on Current Population Survey data. Note as well that not all cards in the sample have valid date-of-birth information. However, these cards remain in our sample because we do not control for age directly; rather we incorporate cardholder fixed effects that control for year-of-birth and other time-invariant factors at the cardholder level.
} 
studied data sets such as the Consumer Expenditure Survey. Our sample is younger, on average, than the US population, so it is possible that some cardholders still receive financial support from family members such that they do not have to spend all of their earned income. Still, the low spending rate in our data, which appears to be fairly constant over time, raises the possibility of measurement error in terms of missing transactions.

More than 90 percent of the cards in our sample are so-called payroll cards, and an investigation of these cards shows regular (weekly or biweekly) deposits from the same source (often employers such as WalMart, Burger King, or Hobby Lobby Stores to name a few) over an extended period of time, suggesting that many cardholders are receiving regular income deposits. That is, the flow of income onto these cards appears relatively stable, which suggests we are potentially missing spending transactions. Indeed, while we observe frequent spending transactions on these cards, the amounts are often small and tend not to sum to the amount of income regularly deposited onto the cards. It is possible we are missing some regular spending by cardholders, such as on rent or similar payments that are paid for by automated clearing house $(\mathrm{ACH})$ transfers from the cards and not well captured by Facteus' data providers. ${ }^{24}$

To the extent that we capture most but not all of cardholders' spending data, we are faced with measurement error in our dependent variable. Assuming that our card-level spending data are measured with error, we speculate that what we observe is the combination of the true level of expenditures, a card-specific constant (capturing the average amount of missing spending), and an error term (random noise). ${ }^{25}$ We assume that missing spending has an average cardholder-specific component based on our observation that spending rates within cards over time are generally stable.

Assuming that there is measurement error of this form, it should mostly, if not completely, be addressed by our empirical setup and therefore not impact our MPC estimates. In particular, our cardholder fixed effects will capture the average card-level missing spending, and any deviations from that average will be absorbed in the error term of our regressions and should not be correlated with our income measures. (Cardholder fixed effects also account for the fact that some cardholders may be thrifty while others may tend to spend all of

\footnotetext{
${ }^{24}$ Our contacts at Facteus suggested that this was indeed a likely explanation.

${ }^{25}$ Specifically,

$$
C_{i t}=\tilde{C}_{i t}+\bar{C}_{i}+\epsilon_{i t}
$$
}

where $C_{i t}$ is observed expenditures for cardholder $i$ at time $t, \tilde{C}_{i t}$ is true expenditures, $C_{i}$ is a cardholderspecific constant (average missing spending amount), and $\epsilon_{i t}$ captures random noise in observed expenditures. 
their money.) As part of our robustness analysis in section 3.2, we restrict our estimation sample to cards with the most stable spending rates over time to test our assumption that cardholder fixed effects are picking up any average missing spending data. In addition, our estimates include location-based time effects, which will pick up any common (external) factors that are potentially correlated over time with the average level of missing spending transactions. What our empirical setup does not capture are missing spending data that are time varying at the cardholder level. This is a concern if the factor(s) driving this time variation is correlated with income. While we cannot completely rule out such a scenario, we think that it is unlikely. We also check and show that our results are robust to allowing for time-varying cardholder fixed effects, as we discuss further in section 3.2. Overall, while the spending rate in our sample is smaller than expected, it should not impact our estimates of interest given our empirical setup.

\section{Results}

\subsection{Baseline Results}

We estimate Equation 1 using OLS based on weekly data starting January 6, 2019, and going through the week ending December 27, 2020. ${ }^{26}$ Figure 1 shows our baseline results, plotting the cumulative spending response to income, EIP1, and tax refund receipts. The solid lines depict the cumulative MPC estimates, while the dashed (same color) lines show the 95 percent confidence intervals around these estimates. The cumulative MPC estimates are shown in event time, with period " 0 " representing the week the funds are received (impact effect) and positive numbers representing weeks since receipt. Table A.2 in the Appendix shows select coefficient estimates from Equation 1 that are used in constructing these figures. The adjusted $R^{2}$ of our baseline regression is 32 percent, suggesting that we can explain a fair amount of the variation in weekly spending.

The results in Figure 1 show that cardholders' cumulative MPC out of incomeX is about 20 cents per dollar on impact and moves higher over the next several weeks before leveling off. After 16 weeks the the cumulative MPC out of incomeX is about 46 cents. In comparison, the impact effect of the stimulus payment on spending is lower-around 15 cents - with the cumulative EIP1 effect remaining somewhat below the incomeX effect for a few weeks before rising noticeably above it. After about 16 weeks the cumulative MPC out of the EIP1

\footnotetext{
${ }^{26}$ Our estimates include data from late 2018 based on the lag structure of our empirical setup.
} 
payment is 66 cents per dollar - noticeably higher than and statistically different from the cumulative incomeX (and tax refund) effect. The somewhat delayed response of spending to the stimulus payments could be due in part to the fact that the majority of the payments were received from mid-April through early May 2020, when restrictions on economic activity were high and cardholders' ability to spend the funds may have been somewhat limited - a topic we explore in more detail in section 3.3.

The spending response to tax refunds is also somewhat delayed relative to the response to incomeX, although the cumulative MPC eventually catches up to that of incomeX. Again, the delay could be due in part to the pandemic, as we observe more tax refunds in 2020 than in 2019, and many of the 2020 refunds were deposited in March and April. One might have expected the EIP1 and tax refund effects to be more similar since tax refunds are also often large, one-time sources of income. However, cardholders may have viewed their tax refunds as less of a temporary income receipt compared with the stimulus payments. Cardholders' spending needs may also have been fewer when their tax refunds arrived in 2019 or even prior to the pandemic in $2020 .^{27}$

Overall, the results in Figure 1 highlight that after a somewhat slow initial response, cardholders spent their EIP1 payments at a higher rate than non-stimulus income. Our estimated impact effect for the EIP1 payments is smaller, however, than in the recent literature that focuses on spending in a very narrow window around when cardholders received these payments and does not control for other sources of income. Still, the spending response to all three income sources is relatively large, and the cumulative EIP1 response is broadly consistent with estimates of the spending response to earlier tax rebates in the literature. Importantly, as we discuss further in section 3.2, our results are also qualitatively quite robust - cardholder spending continually responds the most to the stimulus payments, although the differences are not always quite as pronounced as in our baseline sample (Figure 1), where we focus on comparing cards that are as similar as possible across several dimensions.

\subsection{Robustness}

Our baseline estimates are based on a balanced panel of cards over 2019 and 2020. Our results are similar, however, if we relax this assumption and allow for an unbalanced panel of

\footnotetext{
${ }^{27}$ The tax refund effect is also more precisely estimated than the MPC out of the stimulus likely because there is more variation within the year as to when the tax refunds were received and there is also variation in payments across years in our sample.
} 
cards that received an EIP1 payment. In particular, Figure 2 compares our baseline results (left panel) with a set of estimates (right panel) for which we maintain all of our baseline sample restrictions except the requirement that cards were in the sample for 50 weeks or longer in 2019 and 2020 rather than 100 weeks or longer. Qualitatively, the pattern of results is very similar to our baseline findings. The main differences are that the stimulus effects are more precisely estimated with the unbalanced sample due to the additional cards $(28,510$ unique cards compared with 6,940) and the cumulative MPC estimates out of income are somewhat higher at each horizon, leading to a greater separation between the cumulative incomeX and tax refund effects compared with the separation in our baseline estimates.

Our baseline sample includes only cards with at least one tax refund payment in addition to an EIP1 payment. As noted earlier, we make this sampling choice in order to compare the spending behavior of cards that are as similar as possible. However, not all taxpayers receive refunds in a given year, and there are many cards (about an additional 4,000) that otherwise meet our sample criteria. Figure 3 shows results when we relax the restriction that cards must have had at least one tax refund of $\$ 100$ or more in 2019 or 2020. Again, the results are qualitatively quite similar to our baseline findings, with the incomeX effect largest upon impact and the EIP1 effect delayed a bit before eventually rising somewhat above the incomeX effect. The cumulative MPC out of incomeX is also somewhat higher after about four weeks than in our baseline results, and the cumulative tax refund effects are somewhat lower. Regardless, the general story remains the same, with cardholders' exhibiting the largest cumulative MPC out of the stimulus payments after 16 weeks compared with the other (temporary) income sources.

The results in Figure 5 separate the prepandemic spending rates out of incomeX and tax refund payments from spending responses during the pandemic period, while maintaining common fixed effects across periods, to test whether there were systematic differences in cardholders' spending behavior during the pandemic. ${ }^{28}$ We find that the MPC out of incomeX during the pandemic is similar to what it was before the pandemic, and the same is true for the MPC out of tax refunds, indicating that cardholders did not noticeably alter their spending response to income fluctuations during the pandemic. This result also suggests that the larger spending response to the stimulus payments compared with the response to the non-stimulus income was not an artifact of broader shifts in cardholder spending behavior

\footnotetext{
${ }^{28}$ We define the pandemic period as starting with the week ending March 15, 2020. The prepandemic period is all weeks prior to that one. Since there were no prepandemic stimulus payments, we cannot split the response to those income receipts.
} 
during the pandemic or due to differences over time, for instance, in the number of spending transactions missing from the data set. Indeed, if missing data were affecting our results disproportionally over time, there would be differences in the observed spending responses to other forms of income as well.

As a further check that the lower than expected spending rates out of income in our sample are not impacting our results, we re-estimate Equation 1 after dropping cards with spending rates out of income that are highly variable from 2019 to 2020. ${ }^{29}$ We run this regression to allay concerns that our results may be biased if our cardholder fixed effects are not sufficient to control for average missing expenditures. Indeed, our cardholder fixed effects should do a better job capturing missing expenditure when they are roughly constant over time, or relatedly, when cardholders' spending rates relative to income are roughly constant. We find very similar results after imposing these restrictions, which suggests that any measurement error in our expenditure data has little, if any, effect on our results. ${ }^{30}$ As a further check, we allow for time-varying cardholder effects to address the concern that missing expenditure data could be time varying. ${ }^{31}$ Figure 4 shows these results (right panel), which again are very similar to our baseline results (left panel). The main difference is that the cumulative stimulus effects are slightly lower and less precisely estimated, while the rebate effects are a touch higher. Overall, our findings are robust to additional approaches for addressing potential measurement error in our spending data.

We consider several additional robustness checks (not shown) including restricting our analysis to cards that had received an EIP1 as of April 19, 2020, to better match the period studied by Karger and Rajan (2021). ${ }^{32}$ Our results are very similar with this restriction. ${ }^{33}$ The results are also quite similar if we require that cardholders received a tax refund payment in both 2019 and 2020, as opposed to our baseline restriction that cardholders have at least one tax refund. With this restriction, the cumulative MPC out of tax refunds is, if any different, slightly higher than in our baseline results (not shown), while the cumulative

\footnotetext{
${ }^{29}$ Specifically, we calculate the standard deviation of total consumption relative to total income within cards across years and drop cards in the top 5 percent of the distribution.

${ }^{30}$ These results are available upon request.

${ }^{31}$ Specifically, we allow our cardholder fixed effects to vary over six-month windows in 2019 and 2020.

${ }^{32}$ The April 10-15 period studied by Karger and Rajan (2021) spans two weeks (ending Sunday) in our data, so we include both of those weeks in this analysis.

${ }^{33}$ The vast majority of cards in our sample received a stimulus payment between mid-April and early May 2020 .
} 
MPC out of the EIP1 payments and the cumulative MPC out of IncomeX are essentially unchanged. Our findings are also robust to card-type fixed effects (payroll versus general purpose), including cards with more than one observed EIP1 payment. In addition, they are robust to alternative approaches to winsorizing (or trimming) the spending and income data, and to the inclusion or exclusion of state tax refunds in our measure of incomeX. These results are available upon request. Overall, our baseline findings are qualitatively (and most often quantitatively) very robust.

\subsection{Extensions}

\section{Spending Response across the Income Distribution}

Cardholders in our sample spent about two-thirds of their stimulus monies after 16 weeks - which is somewhat larger than the amount indicated by most survey-based evidence on the spending response to the EIP1 payments (see, for example, Armantier et al., Coibion, Gorodnichenko, and Weber 2020), but roughly in line with the spending response to previous fiscal stimulus, including the response observed in Parker et al. (2013) to the 2008 tax rebates. ${ }^{34}$ The fact that the members of our low-income sample of cardholders seem to have saved some of their EIP1 payment is also consistent with evidence suggesting that savings increased during the pandemic even for low-income individuals. Indeed, researchers at the JP Morgan Chase Institute show that the largest changes in checking account balances occurred for the lowest-income account holders. ${ }^{35,36}$

We further find, as one would expect, that the spending response to the EIP1 payments increases as cardholder income decreases in our sample. Cards with low 2019 income exhibit stronger spending responses compared with higher-income cards, as shown in Figure $6 .{ }^{37}$

\footnotetext{
${ }^{34}$ Data from the Census Pulse Survey suggest much higher spending rates (around 70 percent) out of the EIP1 payments, however, these survey results are a bit of an outlier. For an overview of these results and more information about the survey, see https://www.census.gov/library/stories/2020/06/how-areamericans-using-their-stimulus-payments.html.

${ }^{35}$ See https://www.jpmorganchase.com/institute/research/household-income-spending/householdfinances-pulse-cash-balances-during-COVID-19 and particularly Figure 4 for additional details.

${ }^{36} \mathrm{~A}$ fairly high percentage of respondents in the survey data also state that they had or planned to use their stimulus monies to pay down debt. For a discussion, see, for example urlhttps://libertystreeteconomics.newyorkfed.org/2020/10/how-have-households-used-their-stimuluspayments-and-how-would-they-spend-the-next/. We currently have limited information on cardholders' debt repayment in our data but plan to pursue this channel further in future work. It is possible that some debt repayment is currently included in our measure of total spending.

${ }^{37}$ We compare low-income cards (those in the bottom quartile of the 2019 income distribution) with cards
} 
Indeed, the spending response to all three income sources is noticeably higher for low-income cardholders compared with everyone else, and while the cumulative MPC out of the stimulus payment is highest overall for low-income cardholders, their cumulative MPC out of incomeX is also a good deal larger than for higher-income cardholders. In addition, the spending response to tax refunds is similar to that of incomeX across cardholder types, as we saw with our baseline estimates. Overall, the results in Figure 6 are consistent with cardholders' spending more of their stimulus payments and non-stimulus income based on likely need.

It is also worth noting that the spending response to the stimulus payments remains strong even for higher-income cardholders - especially compared with their responses to incomeX and tax refunds - consistent with their response to the EIP1 payments being different from the responses to other (temporary) income sources.

\section{Expenditure Response across Spending Subcategories}

The pandemic was a unique economic contraction, and consumer spending was affected by the government-imposed economic shutdowns and restrictions as well as shifts in individuals' spending behavior due to the public health situation and their degree of risk tolerance. Spending in sectors requiring social contact, such as entertainment, recreation, and food services (dining out), was particularly impacted, especially around the time the EIP1 payments went out. As a result, relative to a normal downturn, there were certain sectors where individuals' ability to spend their stimulus monies was much less feasible, and this may have affected their overall spending response to the stimulus payments. (There was also a general shift, especially during the early stages of the pandemic, from spending on services to spending on goods.)

To check whether the nature of the pandemic impacted the cumulative MPC out of the EIP1 payments, we re-estimated Equation 1 using broad subcomponents of total expenditures. Specifically, we divide socially distant sensitive spending categories (SDS) from all other spending (nonSDS). Socially distant spending includes expenditures on food services, accommodations, entertainment, travel, and other related categories that require a high degree of social contact - sectors of the economy that were most subject to public health-related restrictions. $^{38}$

in all other income quartiles ("high-income" cards). Our results are qualitatively quite similar if we compare bottom-quartile cards with top-quartile cards only (not shown).

${ }^{38}$ As discussed in section 2.2, we classify spending into broad categories based on the MCC code associated with each transaction. We discuss the MCC codes in more detail in the Appendix, and additional information on our mapping from MCC codes to spending categories is available upon request. 
The spending responses to various income sources for nonSDS expenditures are qualitatively very similar to our baseline results, as shown in Figure 7. This is not necessarily surprising given that nonSDS categories make up the vast majority (about 87 percent on average) of total expenditures in our data. The cumulative MPC estimates across income sources are noticeably different though for SDS expenditures. Not only are the spending responses small given the small share of SDS spending in individuals' overall spending basket, but qualitatively the spending patterns differ from our baseline findings. In particular, the response of SDS spending to the stimulus payments is relatively small and sluggish compared with the spending responses to incomeX and tax refunds. This is especially true in the initial weeks following the stimulus receipt-likely reflecting the fact that individuals' opportunities for SDS spending were extremely limited at the beginning of the pandemic.

Eventually the MPC for SDS spending out of the stimulus payment catches up to that of the other income sources, but not until the end of our horizon for measuring each cumulative MPC. It is worth noting that the sluggish response of SDS spending to stimulus payments compared with other sources of income is robust across alternative (sample) specificationsthe only difference is the speed with which the stimulus MPC catches up to the MPC out of incomeX (not shown). The SDS spending response to tax refunds is also somewhat slower than the response to incomeX, although not as slow as the response to the EIP1 payments, perhaps reflecting cardholders' limited ability to spend 2020 refunds that arrived during the initial stages of the pandemic on SDS items.

While cardholders did not (or could not) spend their stimulus funds on SDS categories, the boost in spending from the stimulus payments relative to expenditures out of normal income was primarily in categories requiring less social contact and/or on items that could more easily be obtained through online shopping and delivery. Figure 8 highlights that, relative to incomeX, a good portion of cardholders' stimulus spending went toward retail as well as other services and to a certain extent durables, although the MPC for durables is smaller overall. ${ }^{39}$ (Keep in mind that our durable goods spending measure may not be comprehensive, since automobiles and similar purchases often must be paid for by cash or check.) Still, our findings showing that cardholders focused their stimulus spending on categories involving less social contact are consistent with the shift in consumers' spending habits associated with the pandemic.

\footnotetext{
${ }^{39}$ Retail is non-grocery retail store spending and includes discount stores, department stores, wholesale clubs, specialty stores, craft stores, jewelry stores, and repair shops. Other services includes insurance, marketing, storage and warehousing, utilities, education and childcare, and charitable organizations.
} 
There is also a fairly strong response of grocery store spending to the stimulus payments as well as tax refunds - especially compared with incomeX (see Figure 9, left panel). This observed effect could reflect cardholders' need for essentials at the start of the pandemic in the face of limited earned income and/or the shift from dining out to eating more often at home for public health (and availability) reasons. The cumulative MPC estimates for other spending categories (not shown) tend to be small and not all that different across income sources. In addition, ATM withdrawals also increase with the stimulus payments and other forms of income. However, these effects are relatively small, and the cumulative effects of the stimulus payments do not differ much from the incomeX effects, suggesting that cardholders did not simply convert their stimulus payments to cash to use for other (unobserved) expenses at a rate that was much faster than normal especially compared with the conversion of nonstimulus income (see Figure 9, right panel). While the different responses across spending categories are interesting, the remainder of our analysis focuses on total expenditures since we are mainly interested in the overall effect of the EIP1 payments.

\subsection{Impact of Pandemic on Stimulus Spending Behavior}

\section{Unemployment Spells}

The economic downturn associated with the pandemic was unique in many ways including the degree to which certain industries and types of workers were affected. Many individuals, and especially low-income workers in customer-facing industries such as food services and retail, were rapidly laid off from their jobs. The EIP1 payments and supplemental unemployment insurance benefits associated with the CARES Act were aimed at replacing income for individuals impacted by the pandemic while stimulating the economy overall. Many of the low-income cardholders in our sample were likely particularly affected by job loss, and we check whether unemployment impacted the spending response to the stimulus payments.

Figure 10 shows the cumulative MPC estimates for cardholders we observe receiving UI benefits during the pandemic and for those we do not observe receiving the benefits. ${ }^{40}$ We find that cardholders who experienced unemployment during the pandemic have a higher cumulative MPC out of the stimulus payment compared with cardholders who did not receive UI benefits but have similar spending responses to incomeX and tax refunds. (Specifically,

\footnotetext{
${ }^{40}$ Some individuals may have been unemployed but live in a state such as California where the benefits are deposited directly onto a stand-alone benefit card and not onto the card we observe in the Facteus data. As a result, we potentially underestimate the number of cardholders who were unemployed, which, if anything, biases us against finding any differential unemployment effect.
} 
we interact a dummy variable for whether or not a card received any UI benefits after March 15, 2020, with all the contemporaneous and lagged income measures in Equation 1.) Even though UI benefits during the pandemic were more generous than usual, we find cardholders who experienced unemployment have a noticeably higher cumulative spending rate out of the stimulus payments (MPC of 0.9 after 16 weeks) compared with cardholders for whom we do not observe evidence of an unemployment spell. (The standard errors around the stimulus effect estimates are large likely because we have a limited number of cards in our sample (around 5 percent) with an observed unemployment spell during the pandemic.) The fact that unemployed cardholders do not exhibit stronger spending responses to incomeX or tax refunds reinforces the idea that despite the overall generosity of benefits during the pandemic, for some cardholders the stimulus payments provided much needed help to finance their expenditures. ${ }^{41}$

\section{Public Health Restrictions}

The pandemic was also unique in terms of the government-mandated curtailment of economic activity to help limit the spread of the virus. Individuals also altered their behavior due to concerns about their own health and safety. Both of these factors potentially impacted how the stimulus monies were spent, especially compared with the spending out of the tax refunds issued during the economic downturns in 2001 and 2008, which were not driven by public health concerns. In particular, cardholders may have had less desire to spend their stimulus money when they received it if they live in an area where there was a high level of new COVID-19 cases, while their ability to spend it may have been limited by public health-related economic restrictions. We therefore examine whether cardholders' MPC out of the EIP1 payments and their MPC out of non-stimulus income differ based on the public health situation or measures taken to contain it.

The top panel of Figure 11 shows results when we divide cardholders based on whether they live in a county where there were relatively high numbers of (population-adjusted) new COVID cases. ${ }^{42}$ The results are mixed and generally do not show much evidence of

\footnotetext{
${ }^{41}$ Our results are qualitatively similar if we interact an indicator variable for whether a cardholder was unemployed at the time the stimulus (or other funds) were received. Specifically, we flag cards that have been receiving UI benefits for at least four weeks at a given point in time.

${ }^{42}$ Specifically, we interact an indicator variable for whether the cardholder lives in a county with an abovemedian rate of new COVID cases in a given week with our three income measures and their respective lags. Dates before March 15, 2020, when there were few if any recorded COVID cases, are assigned a different value of the indicator, so they are not dropped from the analysis nor are they included with the "low" case
} 
high case counts limiting cardholders' desire to spend. The stimulus response in high case count areas is perhaps somewhat greater early on than in low case count areas, whereas the cumulative MPC estimates are generally lower in high case count areas for spending out of tax refunds. Both results lack precision, and spending out of incomeX is little changed, suggesting cardholders living in areas with a worse public health situation did not alter their typical spending behavior substantially compared with cardholders in locations where the virus spread was more limited. Overall, our results suggest that the public health situation at the time stimulus monies were received did not matter much for the degree of stimulus spending that occurred. ${ }^{43}$

Next, we divide cardholders based on whether they live in a state where there was a high degree of government restrictions on activity (containment) in a given week. ${ }^{44}$ Overall, there are not large differences in spending rates out of income - especially for incomeX and tax refunds - across cardholders living in areas subjected to different degrees of containment. If anything, the stimulus effect is larger in areas with high containment, which is not necessarily the expected result if one believes that containment limited individuals' ability to spend their stimulus monies. These estimates are quite noisy, however, and sensitive to the specification. Altering the definition of high containment (defining it as the top quartile of the distribution and "low containment" as the bottom quartile) or changing the sample (allowing cards without tax rebates) yield results suggesting that the spending response to the EIP1 payments was strong but somewhat delayed in high-containment areas compared with low-containment areas. A delayed spending response is consistent with cardholders' having had limited ability to spend their stimulus monies locally in areas where there was a high degree of containment. In addition, the stronger spending response we observe in Figure 11 in high-containment areas could reflect that there was a greater need for the stimulus

count group.

${ }^{43}$ The cumulative spending response to stimulus payments is somewhat lower in high case count areas when our analysis includes cards that do not have a tax refund (not shown).

${ }^{44}$ Again, we interact an indicator variable for whether the cardholder lives in a state where there was a high degree of containment (above the median) or low degree (below the median) with our three income measures and their respective lags. Dates before March 15, 2020, when there was little if any containment, are assigned a different value of the indicator, so they are not dropped nor are they included with the "low-containment" group. The containment data come from IHS/Markit and are based on a subjective ranking of the degree of restrictions in seven different areas: schools/childcare, restaurants/bars, nonessential shops/services, public gatherings, internal mobility, external borders, other (mask mandates, curfews, work-from-home guidance, etc.) 
payments in these locations due to a greater degree of economic shutdown and job loss. ${ }^{45}$

Overall, the public health situation seems to have had some impact on how consumers responded to the stimulus payments and other sources of income, but the estimates are noisy and not necessarily what one might have expected ex ante - especially in terms of cardholders' ability to go out and spend their stimulus payments. The lack of clear spending patterns based on the relative degree of new COVID-19 cases in a given location and the measures taken to contain the virus could also reflect the extent to which consumers and firms fairly quickly, and somewhat unexpectedly, adapted to the constraints imposed by the pandemic. Generally speaking, our results suggest that there was greater heterogeneity in cardholders' cumulative spending response to the EIP1 payments based on unemployment spells, income, and type of expenditure than there was in terms of the public health situation.

\section{Related Literature from Previous Tax Rebates}

The prepandemic literature on the spending response to fiscal stimulus is fairly extensive, starting with Shapiro and Slemrod (2003) and Johnson, Parker, and Souleles (2006). Both papers analyze the 2001 tax rebate, which provided $\$ 300$ checks to individuals and $\$ 600$ checks to married couples filing jointly. Using the Michigan Survey of Consumers, Shapiro and Slemrod (2003) find that roughly 22 percent of respondents said they would mostly spend their tax rebate, 32 percent said they would increase their saving, and 46 percent said they would mostly pay off debt. Somewhat surprisingly, they also find that low-income recipients were not more likely to spend their stimulus funds. Johnson, Parker, and Souleles (2006) take a more quantitative approach and examine data from the Consumer Expenditure Survey (CEX), making use of random variation in the timing of when consumers received their 2001 stimulus check. ${ }^{46}$ In particular, they regress consumption growth on a series of controls (not including income) and a dummy variable for whether the rebate was received in a given period, the dollar amount of the rebate received, or a distributed lag of the rebate indicator variable. They find that households spent 20 to 40 percent of the rebate on nondurable consumption goods during the quarter in which the rebate was received. In contrast to Shapiro and Slemrod (2003), they further show that, consistent with theory,

\footnotetext{
${ }^{45}$ The unemployment rate in Massachusetts and in other states in the Northeast was much higher and stayed higher longer than in other parts of the country in part because of the greater degree of government restrictions on businesses and consumer activity.

${ }^{46}$ Special questions were added to the CEX about when respondents received their stimulus funds, which were distributed based on the last two (random) digits of individuals' social security numbers.
} 
families with low incomes or low liquid wealth exhibited larger spending responses. We also find larger effects for lower-income cardholders in our sample.

In addition, Agarwal, Liu, and Souleles (2007) examine the spending (and debt) response to the 2001 tax rebates using a proprietary data set containing monthly transaction information for 75,000 credit card accounts. Their empirical setup allows the effects of the tax rebate to persist for as long as nine months after its initial receipt. They find, among other things, a cumulative spending response of about 12 percent of the average rebate amount. Their approach is similar to ours in that they use (credit) card-based transaction data and allow for the effects of the stimulus payments to build over time. However, they find stimulus effects for the 2001 rebates that are much smaller than the effects that the other authors find. Similar to these papers, our analysis controls for cardholders' non-stimulus income, and we have a lower-income sample, which is relevant for studying the EIP1 payments that were phased out at higher income levels. ${ }^{47}$

Several subsequent papers examine the spending response to the 2008 tax rebates, including Parker et al. (2013), Shapiro and Slemrod (2009), and Broda and Parker (2014). These studies generally find somewhat smaller spending responses compared with the responses to the 2001 rebates, although the relative size of the estimated effects depends a bit on the study. Shapiro and Slemrod (2009) find that only about 20 percent of survey respondents said they would mostly spend the rebate and conclude that the rebates had low "bang for the buck." Parker et al. (2013) find a somewhat smaller initial nondurable spending response (12 percent of the payment amount) compared with the response to the 2001 rebate, but a fairly substantial total consumption effect (52 percent of the rebate) - an effect that is somewhat smaller than the cumulative effect we find for the 2020 stimulus payments. Broda and Parker (2014) use scanner data from Nielsen and show that spending increased by $\$ 12$ or about 10 percent of average spending in the week the rebate was received. Their empirical setup, like ours, allows for spending out of the stimulus payment to occur over time, and they show that consumers spent 31 to 46 percent of the rebate amount in the quarter it was received and 20 to 29 percent of the amount in the quarter following disbursement. ${ }^{48}$

\footnotetext{
${ }^{47}$ The phaseout started at $\$ 75,000$ (\$150,000 if married and filing jointly), and individuals with 2019 income greater than $\$ 99,000$ ( $\$ 198,000$ if married filing jointly) did not qualify. See https://www.irs.gov/ newsroom/calculating-the-economic-impact-payment for more details.

${ }^{48}$ The effects in Broda and Parker (2014) are based on rescaling the Nielsen data, which captures spending only on goods with barcodes - primarily food and drugstore products, small appliances and electronic goods, and mass merchandise products excluding apparel - to generate a measure of total expenditures. The data also do not contain information about individuals' non-stimulus income.
} 
In addition, Broda and Parker (2014) and Parker et al. (2013) find that, as with the 2001 rebates, less affluent individuals had larger spending responses. In comparison, Shapiro and Slemrod (2009) find that lower-income households were more likely to report they would use the 2008 stimulus funds to pay off debt. Lastly, Sahm, Shapiro, and Slemrod (2012) examine whether the spending response was larger with the 2008 rebate or the 2009 payroll tax cut (the Making Work Pay tax credit) and find that the payroll tax cut boosted spending by about half the rate of the 2008 stimulus checks.

\section{Conclusion}

In this paper we analyze the spending response in the United States to the government stimulus payments associated with the 2020 CARES Act using high-frequency, transactionlevel data for a sample of lower-income, largely unbanked individuals. Unlike many previous studies, we control for cardholders' non-stimulus income both because the data are available to us and because the nature of the pandemic was such that stimulus payments may not have been orthogonal to other income changes at the time, especially for lower-income workers.

In a robust specification that includes cardholder, time, and location effects, we find a cumulative spending response to the first round of fiscal stimulus payments (EIP1) that is relatively large and stronger than the spending responses to other forms of temporary income. We demonstrate that this result is quite robust and further show that the cumulative MPC out of the stimulus payments is larger for lower-income cardholders in our sample and highlight that the spending response was likely impacted to a degree by the nature of the pandemic and the restrictions imposed to help improve the public health situation. We also find a larger MPC for cardholders we observe as being unemployed during the early part of the pandemic - a finding that a priori is not necessarily expected given the generosity of government benefits at the time.

While the analysis in this paper focuses on only the first round of stimulus payments, the nature of the economic downturn associated with the pandemic - especially early on, when the vast majority of the EIP1 payments were disbursed - was unique, and thus our findings provide insight into the efficacy of fiscal policy in response to a public health shock. Likely relevant insights also can be gained by comparing the spending response to the EIP1 payments with the responses to the two rounds of stimulus payments that occurred in early 2021, when the public health and economic situations in the United States were somewhat improved. There is also variation in the size of the stimulus payments, which could lead to 
varied spending responses by cardholders. That is, a $\$ 600$ payment might be spent more rapidly or fully rather than a larger payment, which might be partially saved due to a lack of need or items on which to spend all of the money. We plan to pursue these ideas, and to look more closely at the relationship between stimulus funds and debt repayment, in subsequent work extending the analysis in this paper. 


\section{References}

Agarwal, Sumit, Chunlin Liu, and Nicholas S. Souleles. 2007. "The Reaction of Consumer Spending and Debt to Tax Rebates: Evidence from Consumer Credit Data." Journal of Political Economy 115(6): 986-1019.

Armantier, Olivier, Leo Goldman, Gizem Koar, Rachel Pomerantz Jessica Lu, and Wilbert van der Klaauw. "How Have Households Used Their Stimulus Payments and How Would They Spend the Next?" Liberty Street Economics.

Available at https://libertystreeteconomics.newyorkfed.org/2020/10/how-havehouseholds-used-their-stimulus-payments-and-how-would-they-spend-the-next.html.

Baker, Scott R, R. A Farrokhnia, Steffen Meyer, Michaela Pagel, and Constantine Yannelis. 2020. "Income, Liquidity, and the Consumption Response to the 2020 Economic Stimulus Payments." Working Paper 27097. National Bureau of Economic Research.

Available at http://www.nber.org/papers/w27097.

Baugh, Brian, Itzhak Ben-David, Hoonsuk Park, and Jonathan A. Parker. 2021. "Asymmetric Consumption Smoothing." American Economic Review 111(1). Available at https://www.aeaweb.org/articles?id=10.1257/aer.20181735.

Broda, Christian, and Jonathan A. Parker. 2014. "The Economic Stimulus Payments of 2008 and the Aggregate Demand for Consumption." Journal of Monetary Economics 68: S20-S36.

Available at https://www.sciencedirect.com/science/article/pii/S0304393214001366.

Coibion, Olivier, Yuriy Gorodnichenko, and Michael Weber. 2020. "How Did U.S. Consumers Use Their Stimulus Payments?" Working Paper 27693. National Bureau of Economic Research.

Available at http://www.nber.org/papers/w27693.

Cox, Natalie, Peter Ganong, Pascal Noel, Joseph Vavra, Arlene Wong, Diana Farrell, Fiona Greig, and Erica Deadman. 2020. "Initial Impacts of the Pandemic on Consumer Behavior: Evidence from Linked Income, Spending, and Savings Data." Brookings Papers on Economic Activity (SI): 35-69. 
Johnson, David S., Jonathan A. Parker, and Nicholas S. Souleles. 2006. "Household Expenditure and the Income Tax Rebates of 2001." American Economic Review 96(5): 1589-1610. Available at https://www.aeaweb.org/articles?id=10.1257/aer.96.5.1589.

Karger, Ezra, and Aastha Rajan. 2021. "Heterogeneity in the Marginal Propensity to Consume: Evidence from Covid-19 Stimulus Payments." Working paper. Federal Reserve Bank of Chicago.

Parker, Jonathan A., Nicholas S. Souleles, David S. Johnson, and Robert McClelland. 2013. "Consumer Spending and the Economic Stimulus Payments of 2008." American Economic Review 103(6): 2530-53. doi:10.1257/aer.103.6.2530.

Available at https://www.aeaweb.org/articles?id=10.1257/aer.103.6.2530.

Sahm, Claudia R., Matthew D. Shapiro, and Joel Slemrod. 2012. "Check in the Mail or More in the Paycheck: Does the Effectiveness of Fiscal Stimulus Depend on How It Is Delivered?" American Economic Journal: Economic Policy 4(3): 216-250.

Shapiro, Matthew D., and Joel Slemrod. 2003. "Consumer Response to Tax Rebates." American Economic Review 93(1): 381-396.

Available at https://www.aeaweb.org/articles?id=10.1257/000282803321455368.

Shapiro, Matthew D., and Joel Slemrod. 2009. "Did the 2008 Tax Rebates Stimulate Spending?" American Economic Review 99(2): 374-79. doi:10.1257/aer.99.2.374. Available at https://www.aeaweb.org/articles?id=10.1257/aer.99.2.374. 
Figure 1. Baseline Results: Cumulative Spending Response by Income Source

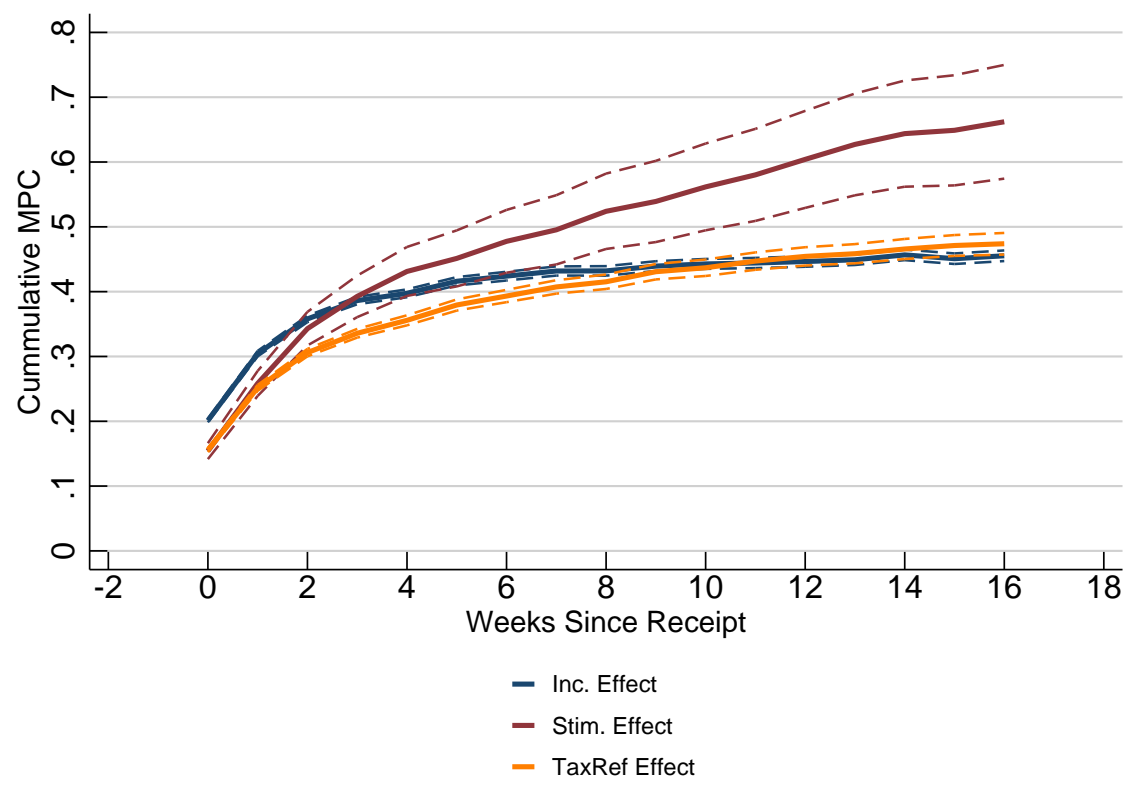

Source: Authors' calculations using the Facteus US Consumer Payments data panel.

Figure 2. Robustness: Balanced versus Unbalanced Sample

Baseline Sample (Balanced)

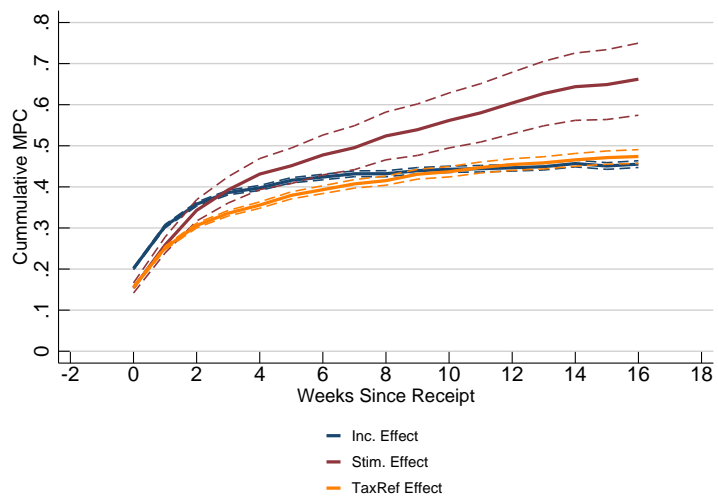

Unbalanced Sample

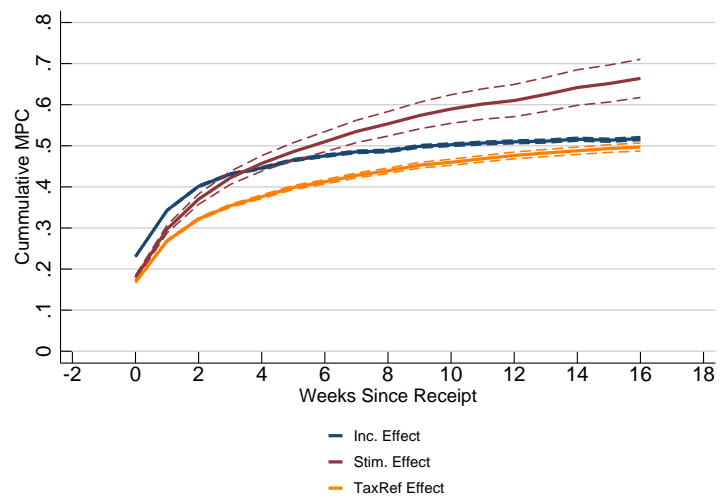

Source: Authors' calculations using the Facteus US Consumer Payments data panel.

Notes: Balanced Panel: Cards must appear for 100 weeks or more in 2019 and 2020. Unbalanced Panel: Cards must appear for 50 weeks or more in 2019 and 2020. All other sample requirements match our baseline criteria. 
Figure 3. Robustness: Cards with and without Tax Refunds

Baseline Sample (Have Refund)

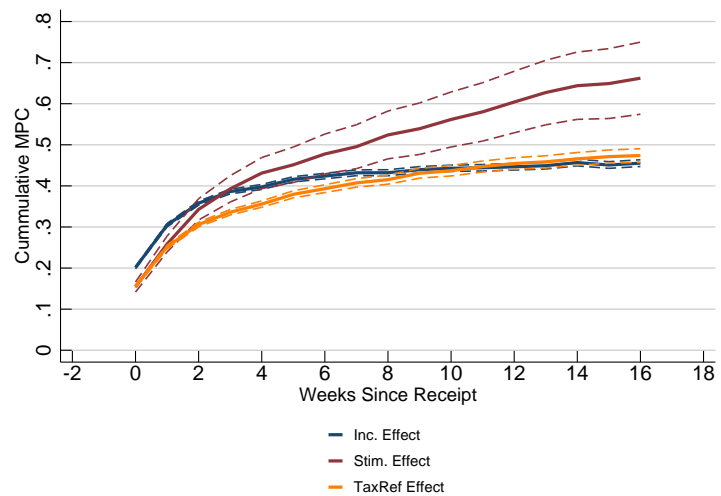

Alternative (Cards without Refunds)



Source: Authors' calculations using the Facteus US Consumer Payments data panel.

Notes: Alternative sample allows cards to be in the sample that do not have an observed tax refund in 2019 or 2020. All other sample requirements match our baseline criteria.

\section{Figure 4. Robustness: Time-varying Cardholder Fixed Effects}

Baseline Sample

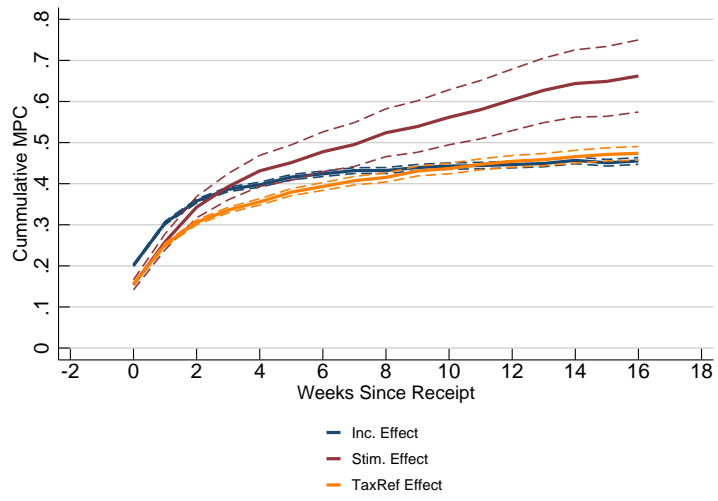

Baseline w Time-varying Fixed Effects

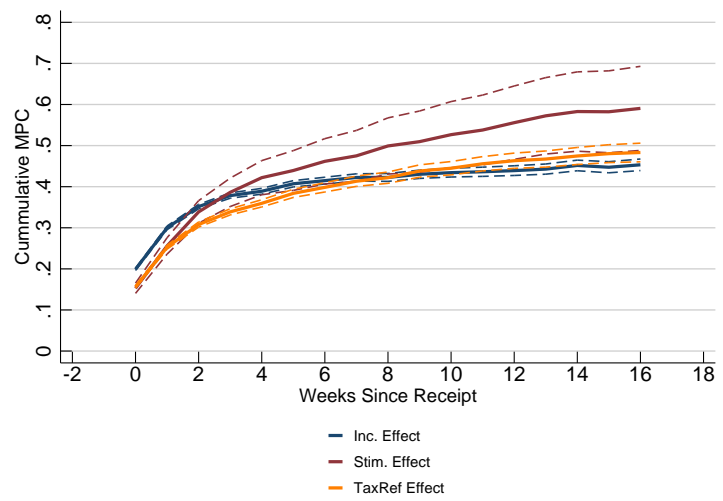

Source: Authors' calculations using the Facteus US Consumer Payments data panel.

Notes: Right panel: cardholder fixed effects are allowed to vary over 6-month periods in 2019 and 2020. All other sample requirements match our baseline criteria. 
Figure 5. Extensions: Spending before and during the Pandemic

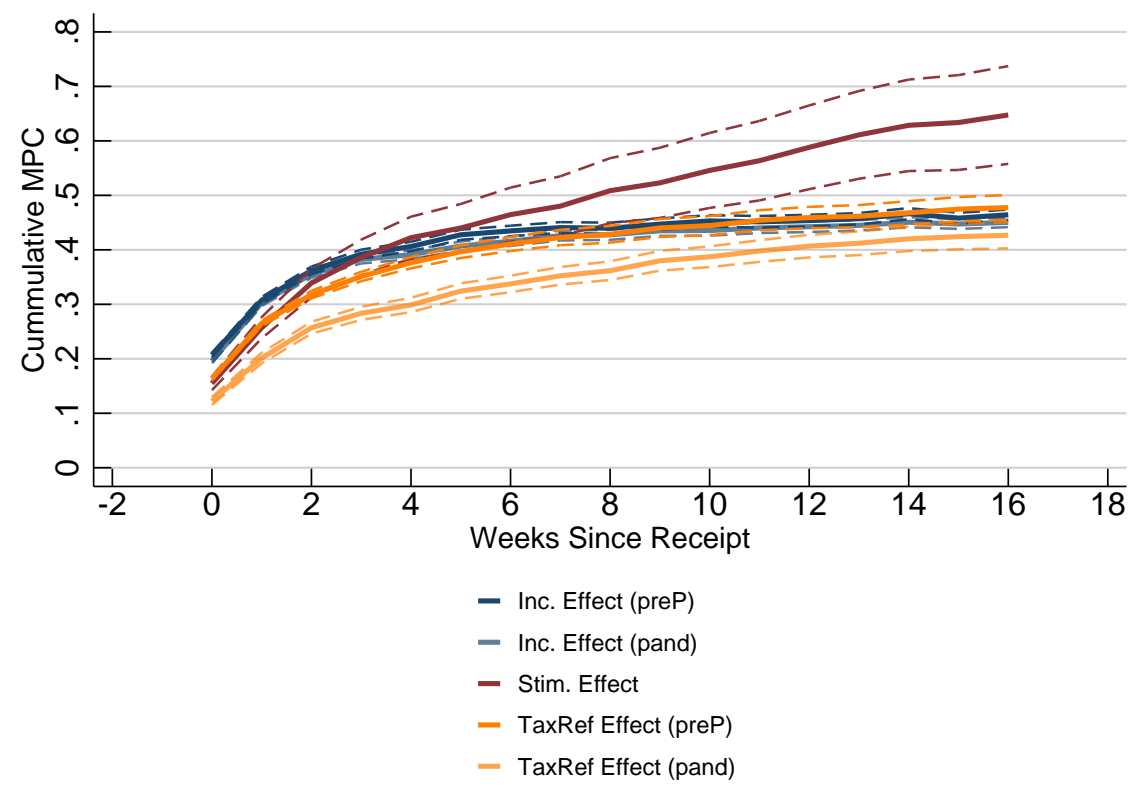

Source: Authors' calculations using the Facteus US Consumer Payments data panel. Notes: preP: period prior to March 15, 2020. pand: period from March 15, 2020, onward.

Figure 6. Extensions: Splits by Cardholder Income
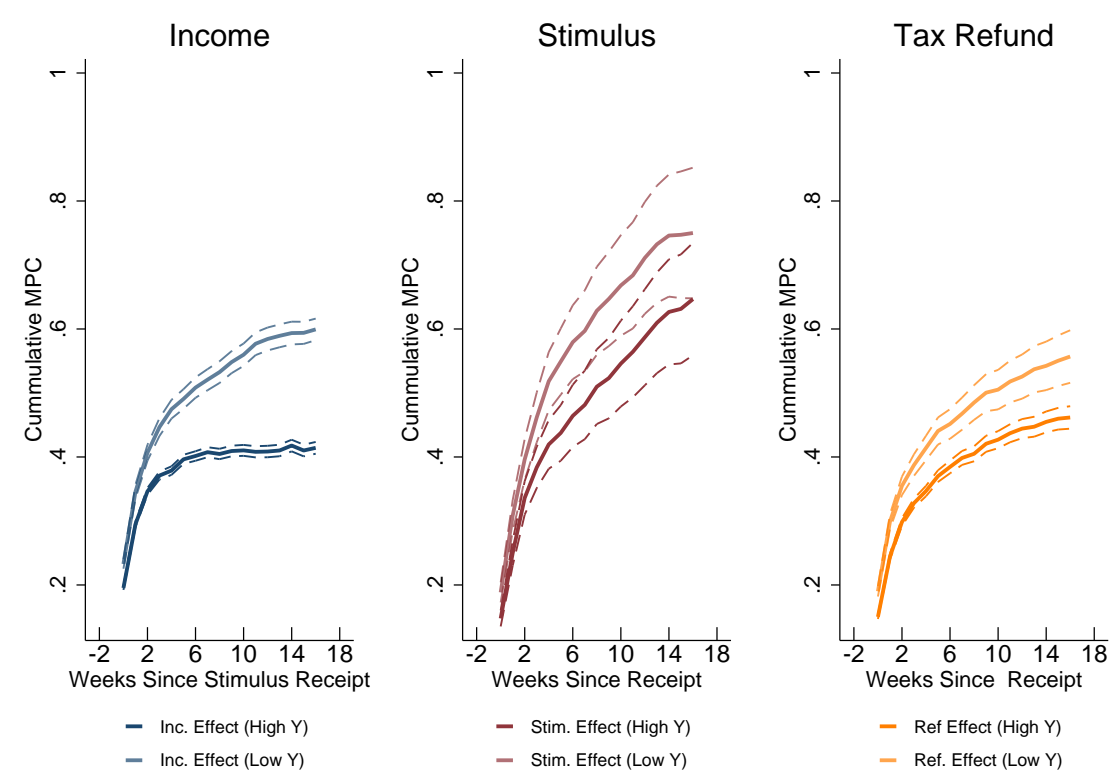

Source: Authors' calculations using the Facteus US Consumer Payments data panel.

Notes: Low Y: cards in the bottom quartile of the 2019 income distribution. High Y: all other cards in the 2019 income distribution. See text for additional details. 
Figure 7. Extensions: Splits by Broad Expenditures Type (SDS vs. NonSDS)
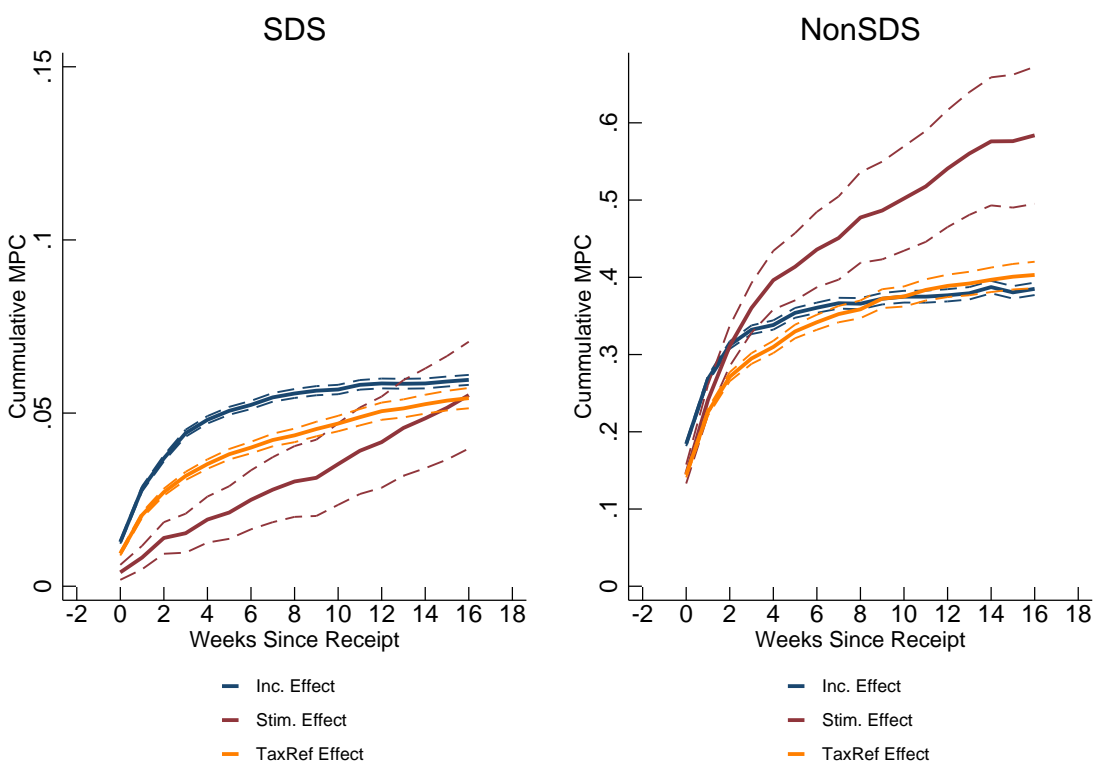

Source: Authors' calculations using the Facteus US Consumer Payments data panel

Notes: SDS: expenditures in social distance sensitive sectors as defined in the text. NonSDS: expenditures in all other sectors not requiring a high degree of social contact.

\section{Figure 8. Extensions: Select Expenditure Categories}


Source: Authors' calculations using the Facteus US Consumer Payments data panel.

Notes: Retail is non-grocery retail store spending as defined in the main text. Other services includes insurance, marketing, storage and warehousing, utilities, education and childcare, and charitable organizations. 
Figure 9. Extensions: Additional Expenditure Categories
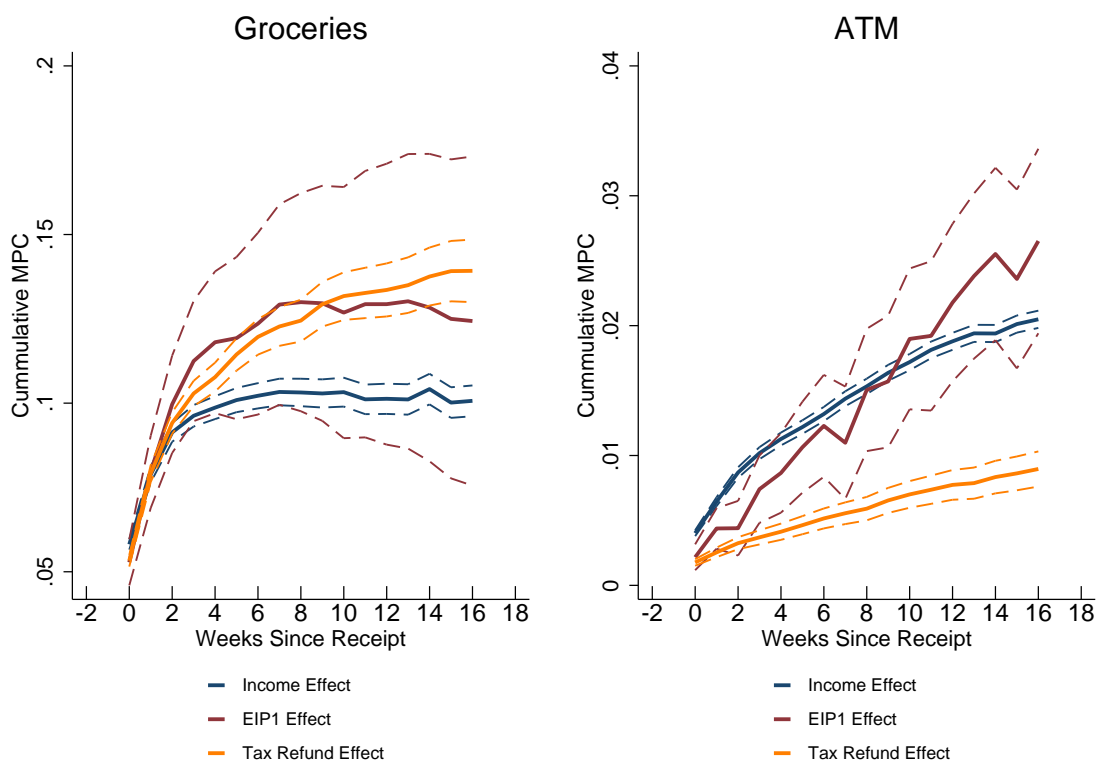

Source: Authors' calculations using the Facteus US Consumer Payments data panel. Notes: ATM is (cash) withdrawals from the cards at automatic teller machines.

Figure 10. Extensions: Splits by Unemployment Status during Pandemic
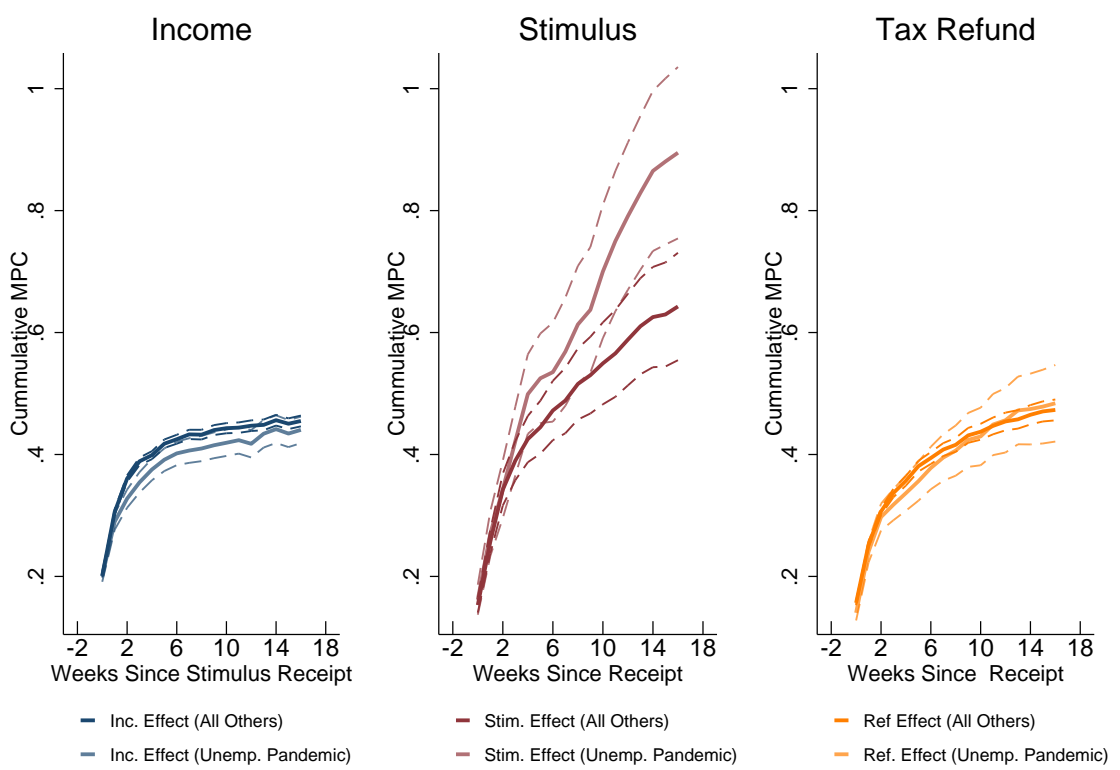

Source: Authors' calculations using the Facteus US Consumer Payments data panel.

Notes: Unemp Pandemic: cards with unemployment spell during pandemic (those with observed UI benefit payments any time from March 15, 2020, onward). All Others: cards without observed UI benefits during pandemic. See text for additional details. 
Figure 11. Extensions: Spending and the Public Health Situation

(a) Splits by COVID-19 Case Count Growth


(b) Splits by Degree of Containment
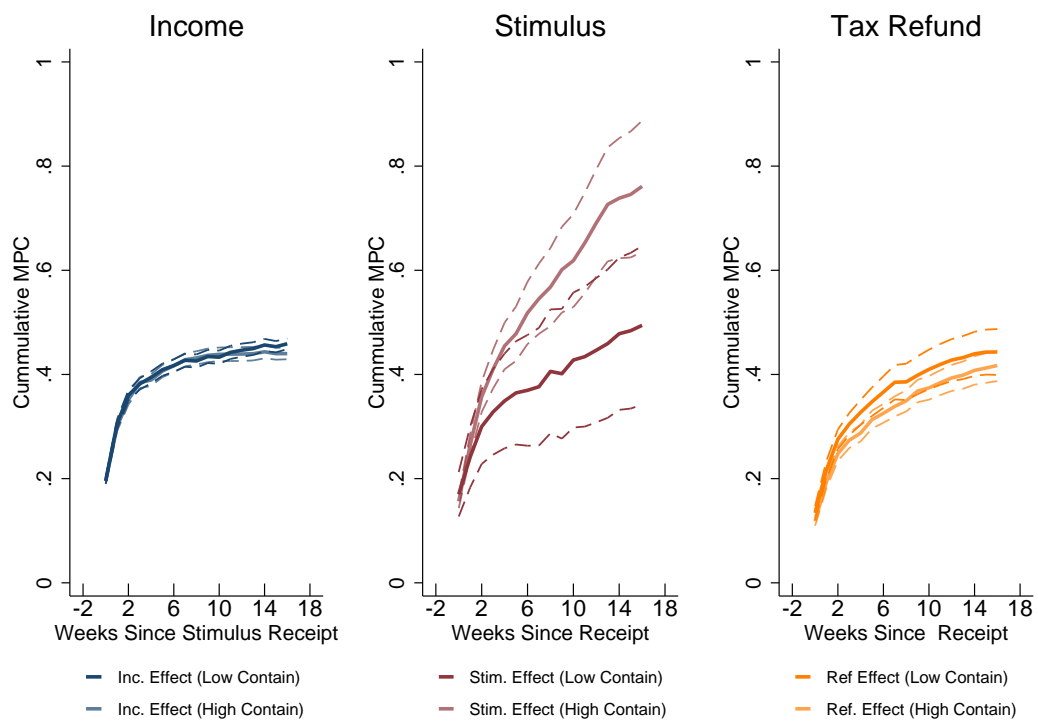

Sources: New York Times/IHS Markit/Authors' calculations using the Facteus US Consumer Payments data panel.

Notes: High Cases: cardholders located in counties with above median new cases of COVID-19 relative to population in a given week. Low Cases: cardholders living in counties with below median new cases. High Contain: cardholders living in a state with a high degree of (above median) economic restrictions. Low Contain: cardholders living in a state with lower (below median) economic restrictions. 
Table 1. Summary Statistics: Baseline Sample Cards

\begin{tabular}{lcccccc}
\hline \hline \multicolumn{1}{c}{ Variable } & Mean & Median & Std. Dev. & Min. & Max. & N \\
\hline Income 2019 & 24337.5 & 22616.3 & 10021.5 & 1292.2 & 101630.9 & 6940 \\
Income 2020 & 28117.6 & 26071.9 & 11366.2 & 2512.4 & 128584.7 & 6940 \\
Spending 2019 & 15191.1 & 14619.8 & 6936.2 & 0.0 & 72631.4 & 6940 \\
Spending 2020 & 17262.7 & 16468.5 & 7881.7 & 161.4 & 67593.3 & 6940 \\
IncomeX 2019 & 23363.3 & 21710.0 & 9760.9 & 1292.2 & 101630.9 & 6940 \\
IncomeX 2020 & 25567.2 & 23530.2 & 11102.7 & 1278.9 & 126882.8 & 6940 \\
Avg Wkly Spending & 312.4 & 302.6 & 127.5 & 5.7 & 1120.8 & 6940 \\
Avg Wkly IncomeX & 462.7 & 438.0 & 168.6 & 27.3 & 1473.8 & 6940 \\
EIP1 amount & 1292.4 & 1205.1 & 251.6 & 1163.8 & 4640.7 & 6940 \\
Age & 39.2 & 36.0 & 12.9 & 17.0 & 84.0 & 6586 \\
Amt. Tax Refund 2019 & 1318.8 & 991.1 & 1145.6 & 2.0 & 4999.9 & 4982 \\
Amt. Tax Refund 2020 & 1358.0 & 998.3 & 1139.8 & 2.0 & 4998.4 & 6243 \\
Unemp. Spell 2019/20 (\% with) & 5.9 & 0.0 & 23.6 & 0.0 & 100.0 & 6940 \\
Unemp. Spell during Pandemic (\% with) & 5.4 & 0.0 & 22.6 & 0.0 & 100.0 & 6940 \\
Avg. Spending rel. Avg. Income & 0.7 & 0.7 & 0.2 & 0.0 & 5.9 & 6940 \\
Tot. Deposits 2019 & 49.5 & 45.0 & 22.8 & 2.0 & 170.0 & 6940 \\
Tot. Deposits 2020 & 53.4 & 49.0 & 26.5 & 1.0 & 239.0 & 6940 \\
Tot. Spend Trans. 2019 & 542.3 & 507.0 & 254.0 & 0.0 & 1621.0 & 6940 \\
Tot. Spend Trans. 2020 & 564.3 & 530.0 & 262.2 & 4.0 & 1934.0 & 6940 \\
\hline
\end{tabular}

Source: Authors' calculations using the Facteus US Consumer Payments data panel

Notes: Income: total deposits onto the card. IncomeX: deposits (income) onto the card excluding stimulus payments and tax refunds. Not all cards have valid age data. Average spending relative to average income is average weekly spending relative to average weekly income at the card level. See text for additional details. 


\section{A Appendix}

\section{A.1 Supplemental Tables and Figures}

Figure A.1. Geographic Distribution of Cards in Baseline Sample

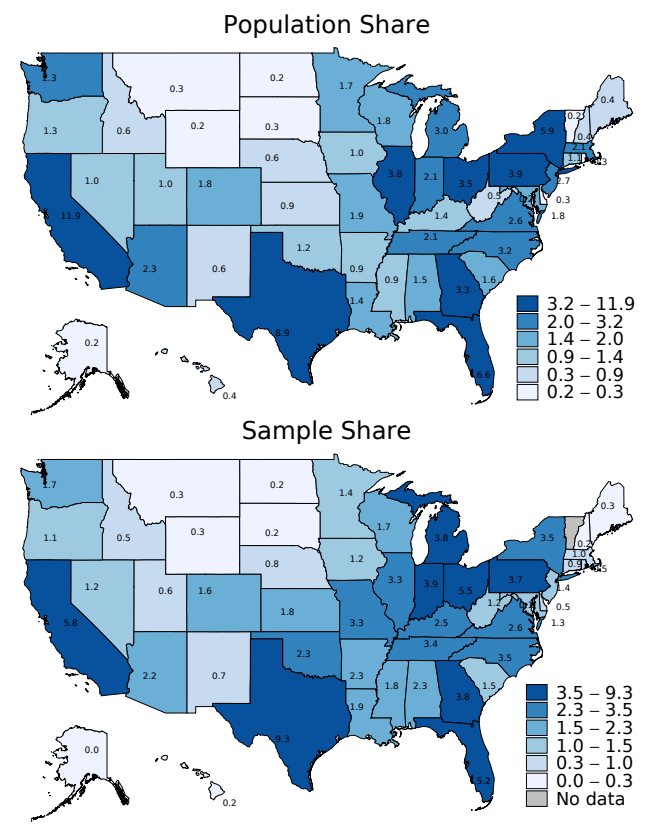

Source: Authors' calculations using the Facteus US Consumer Payments data panel.

Notes: Sample restricted to cards with positive tax rebates in addition to stimulus payments as discussed in the text. 


\section{Figure A.2. Card-type Descriptions}

\begin{tabular}{|c|c|}
\hline Card Types & Detailed Description \\
\hline Benefit - Health & $\begin{array}{l}\text { These cards also known as FSA cards which stands for Flex Spending Account. These cards are attached to person's health benefits provided } \\
\text { through their employer. Cardholders can allocate pre-tax dollars to use on approved medical expenses and those purchases can be made on } \\
\text { these cards. In other words these cards can only be used at specific merchants in pre-approved medical categories (e.g. pharmacy, urgent } \\
\text { care, optometry, eyeglasses/contacts, dentists etc.). }\end{array}$ \\
\hline Debit & $\begin{array}{l}\text { In this Facteus panel, the Debit cards come primarily from "Challenger Banks" like Simple, N26, Chime, Varo, etc. These banks are mobile-only } \\
\text { with no physical branches and heavily target the millennial and GenX age groups. These cards are typically the primary card for these } \\
\text { cardholders. } \\
\text { Millennials are an interesting demographic to study overall given the size (largest generation since Baby Boomers) and behavioral differences } \\
\text { (lowest credit card usage of generations). Millennials have become increasingly important to understand in context of the COVID-19 crisis as } \\
\text { they are still relatively early in their careers and might be susceptible to layoffs or reduced hours. }\end{array}$ \\
\hline Incentive & $\begin{array}{l}\text { These cards are a similar to Visa/MC gift cards. They are distributed by employers for spot bonuses as performance rewards. For example, a } \\
\text { sales team may earn a } \$ 500 \text { bonus for hitting their sales target. The employer would hand out these Incentive Cards with } \$ 500 \text { loaded onto } \\
\text { them. The employee may use the card anywhere just like a Visa/MC gift card. }\end{array}$ \\
\hline General Purpose & $\begin{array}{l}\text { These cards have full debit card functionality. These cards can be swiped at any retailer accepting Visa/MC and can be used at ATMs to } \\
\text { withdraw cash with a PIN. These cards can be loaded with cash deposits or via direct deposit. One of the major differences between General } \\
\text { Purpose Debit Cards is that they are distributed by retailers, stores, or brands, and NOT banks. Most cardholders will obtain a General Purpose } \\
\text { card from a retailer like Walmart or Kroger, or check-cashing stores. The target customer for these cards is those in the lower to middle- } \\
\text { income brackets also referred to as the "underbanked". Many of these people turn to these cards from retailers like Walmart because they } \\
\text { live in lower-income neighborhoods which have become "banking deserts" where there are no bank branches nearby. Retailers like grocery } \\
\text { stores and check cashers have become financial centers for these underbanked populations. } \\
\text { This group of cardholders is extremely susceptible financially to the COVID-19 pandemic. Most of the cardholders in this group are hourly } \\
\text { wage workers in industries directly affected by the "stay at home" orders and the massive layoffs/hour reductions. }\end{array}$ \\
\hline Payroll & $\begin{array}{l}\text { These cards are very similar to the General Purpose cards from a target market perspective. They are typically in the hands of underbanked } \\
\text { individuals as well. The difference in these Payroll cards is how they are distributed. Payroll cards are distributed by employers to their } \\
\text { employees who do not have bank accounts (or have not provided one to their employer). } \\
\text { The employee then receives their paycheck disbursements via direct deposit onto these Payroll cards. The value proposition for the consumer } \\
\text { is that they can receive their paychecks via direct deposit (funds are available immediately) with no need to take their paper check to a check } \\
\text { casher who will charge them } 1 \%-3 \% \text {. For the employer, the value proposition is that they can save money by paying via direct deposit. It costs } \\
\text { employers about } \$ 13 \text { to issue paper checks. } \\
\text { Many franchise businesses like fast food restaurants use Payroll cards to disburse paychecks to their employees. This is another group that is } \\
\text { extremely susceptible to the financial crisis that COVID-19 has caused. }\end{array}$ \\
\hline Government & $\begin{array}{l}\text { These cards are a very specific type of government disbursement card. These cards can be used just like any other Debit card where } \\
\text { cardholders can swipe and spend in-store plus online and withdraw cash with a PIN from an ATM. The cards in this panel are specifically } \\
\text { alimony cards. In these cases, the government steps in and deducts funds directly from the paycheck of one party and deposits the funds onto } \\
\text { one of these Government Cards. }\end{array}$ \\
\hline Gift Card & $\begin{array}{l}\text { These are gift cards with Visa/MC logos which allow them to be used anywhere Visa/MC are accepted. These gift cards can be bought from } \\
\text { most retailers. These cards are not reloadable and once the funds have been used the card is no longer used. }\end{array}$ \\
\hline Corporate Expense & $\begin{array}{l}\text { These are debit cards used for companies to to distribute for corporate expenses. For } \\
\text { facilitated on these types of cards. }\end{array}$ \\
\hline
\end{tabular}

Source: Facteus.

Notes: Figure provides a list of all card types tracked by Facteus. Not all card types are in our data set. 
Table A.1. Example Card with Multiple EIP1 Transactions

\begin{tabular}{lcccc}
\hline ARM_ID_NBR & ARM_TRAN_ID & TXN_DATETIME & TXN_AMT & MRCHNT_NME \\
\hline a14:1...8610C & $770 c 4 \ldots . . c a 846$ & $2020-10-23$ 16:01:51 & 1205.03 & IRS TREAS 310 TAXEIP11GK42 \\
a14:1..8610C & a870f...42ee7 & $2020-11-06$ 16:10:09 & 1206.93 & IRS TREAS 310 TAXEIP1MV0BZ \\
a14:1..8610C & fbaaf...b2780 & 2020-11-06 16:14:48 & 1197.01 & IRS TREAS 310 TAXEIP1AKIS4 \\
\hline
\end{tabular}

Source: The Facteus US Consumer Payments data panel.

Notes: Table shows select fields for a card with multiple EIP1 payments. Column headings correspond to the variable names in the Facteus data set. In order, the columns are: unique card ID number, transaction ID, date/time the transaction occurred, transaction amount, electronic signature associated with the transaction. 
Table A.2. Baseline Results and Alternatives: Select Coefficient Estimates

\begin{tabular}{lccc}
\hline \hline & $(1)$ & $(2)$ & $(3)$ \\
& Baseline & Early Stimulus & Incl. no Refund \\
\hline & & & \\
& & & \\
Income excl. Stim / All Ref & $0.20^{* * *}$ & $0.20^{* * *}$ & $0.22^{* * *}$ \\
& $(0.00)$ & $(0.00)$ & $(0.00)$ \\
Income excl. all (Lag 1wk) & $0.10^{* * *}$ & $0.10^{* * *}$ & $0.11^{* * *}$ \\
& $(0.00)$ & $(0.00)$ & $(0.00)$ \\
EIP1 Amount & $0.15^{* * *}$ & $0.15^{* * *}$ & $0.19^{* * *}$ \\
& $(0.01)$ & $(0.01)$ & $(0.00)$ \\
EIP1 Amount (Lag 1wk) & $0.10^{* * *}$ & $0.11^{* * *}$ & $0.11^{* * *}$ \\
& $(0.01)$ & $(0.01)$ & $(0.00)$ \\
Tax Refund & $0.16^{* * *}$ & $0.16^{* * *}$ & $0.15^{* * *}$ \\
& $(0.00)$ & $(0.00)$ & $(0.00)$ \\
Tax Refund (Lag 1wk) & $0.10^{* * *}$ & $0.10^{* * *}$ & $0.09^{* * *}$ \\
& $(0.00)$ & $(0.00)$ & $(0.00)$ \\
& & & 0.35 \\
& 0.32 & 0.32 & $1,078,040$ \\
\hline Adj. R-squared & 628,924 & 584,902 & \\
Observations & & & \\
\hline
\end{tabular}




\section{A.2 Facteus Data}

\section{Data Overview}

Facteus provides highly detailed transaction-level data for the cards in its panel. For each transaction that occurs, we know the date, time, amount, type of transaction (deposit or spend), and the electronic signature (MRCHNT_NME) associated with the transaction, which provides information on the merchant from which the purchase was made (spend) or the source (originator) of the deposit (income). There is also information on each cardholder's Zip code (of residence) and date of birth. In addition, each card is assigned an anonymous ID number (ARM_ID_NBR), which does not change as long as the card remains in the panel, and any personal identifying information (PII) is scrubbed from the transaction signature by Facteus. Cards enter and exit the sample over time, but we are able to obtain a relatively balanced sample of cards over two-plus years for our baseline analysis. ${ }^{49}$

As noted in the main text, the data set also contains a four-digit merchant category code (MCC), which identifies, at a highly detailed level, the type of merchant from which a purchase is made. ${ }^{50}$ These classifications can be grouped into broader categories (for example, hotels, airlines, grocery stores, etc.), allowing us to generate aggregated spending measures, such as purchases that require social contact versus all others, for our analysis. ${ }^{51}$ Of course, we observe only cardholders' electronic transactions and not purchases made by cash or check. We therefore have limited data, for example, on rent payments and vehicle purchases. ${ }^{52}$ However, we do capture spending on home furnishings and other related biggerticket, durables-type purchases.

Demographic information on any cardholder is limited to their Zip code (of residence) and date of birth (DOB). Importantly, we know where the cardholder resides, not where the

\footnotetext{
${ }^{49}$ According to Facteus, one reason for cards' exiting from the sample is that consumers tend to stop using their employer-issued payroll cards when they change jobs voluntarily or involuntarily. A given cardholder may remain in the sample with a card from a new employer, but it is not possible to track individuals across cards.

${ }^{50} \mathrm{MCC}$ codes are a universal classification system for merchants maintained by the credit card issuers (Visa and Mastercard) and assigned to each merchant's card-reading and processing terminal(s). Categories include "fast food restaurants" (5814) and "glassware/crystal stores" (5950). For more details see https: //usa.visa.com/content/dam/VCOM/download/merchants/visa-merchant-data-standards-manual.pdf.

${ }^{51}$ Our mapping from MCC codes to broader spending categories is available upon request.

${ }^{52}$ Some auto dealers allow credit or debit cards to be used for an initial vehicle deposit, and it is possible that some cardholders pay rent (or a mortgage) via ACH or EFT transfers from their cards. We continue to work to better identify these type of payments, especially rent and other related housing payments, to the extent possible in our data.
} 
transactions occur. However, this is not an issue for our analysis since we are interested in how cardholder spending responds to stimulus and non-stimulus income and not not where the spending occurred. As discussed in the main text, we use the cardholder's location of residence to control for local factors that might influence spending, such as the local spread of COVID-19 or public health-related containment measures. We discuss how we clean the Zip code and DOB data later in this section.

\section{Identifying Stimulus Payments}

We identify stimulus payments from the federal government through a series of steps. As noted in the text, each transaction in the Facteus data set includes an electronic signature stored in the "MRCHNT_NME" field (hereafter MNME). This field provides information regarding the payee or payer associated with the transaction.

First, we conduct regular expression (REGEX) searches of all deposit or load transactions in the Facteus data set to find signatures that are associated with payments from the IRS or US Treasury. These searches are relatively broad in an attempt to capture all possible government payments, but they are informed by some known tax refund and stimulus payment strings along with some initial test searches. In particular, we use the following REGEX: "TREAS(?:U(?:RY?)?)?[]+[0-9][0-9][0-9]|(?:IRS|US|SSI|SSA|OST|TCS)[ ]+TREAS," which allows for different versions of the string "TREASURY" as well as associated numeric fields of at least three numeric digits - consistent with typical Treasury payment signatures - and potential government department abbreviations such as "IRS" or "SSA" (Social Security Administration).

Second, we deduplicate the MNME field to generate a list of common expression "stubs." These include "US TREASURY 312 XXSOC SEC" (Social Security), "US TREASURY 310 XXVA" (VA benefits), and, related to our interests, "IRS TREAS 310 TAX REF," among

others. We search the resulting list of stubs manually for any false positives, which in the end represent an incredibly small share of the overall number of identified Treasury deposits (51 transactions out of 15 million with Treasury-related strings.) False positives include "US TREASURY INTERNAL TEST" and "WASHOE CO TREASU 77532825500MDFQ." The latter matches our REGEX criteria because of the three consecutive digits after "TREASU." We drop these transactions from our results. We further check our approach by looking at the number of unique cards in each month in 2020 that we identify as having a payment from the US Treasury. The number of cards in April 2020 is nearly four times the number in surrounding months, consistent with the fact that the majority of stimulus payments were 
sent electronically in April (not shown). These checks give us confidence in our ability to identify US Treasury payments in the data.

Third, we categorize all the Treasury-related payments based on known strings associated with certain payment types. We use data from the Treasury "Green Book" to help inform this categorization. Figure A.3 show our group assignments.

Figure A.3. Treasury Payment Categories

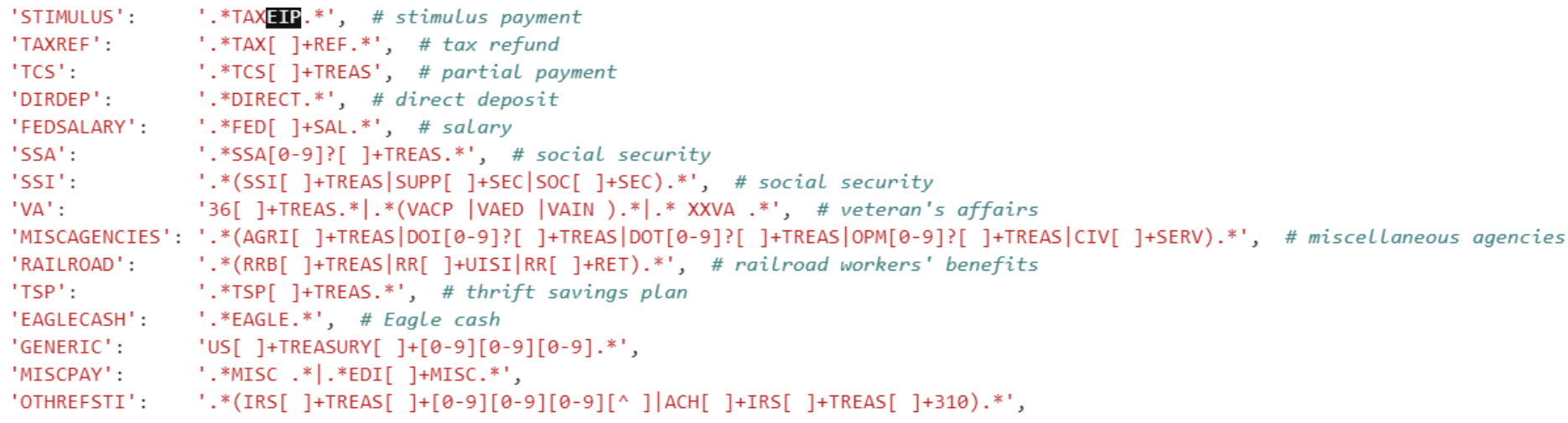

Next, we take steps to identify likely stimulus payments within these payment-type categories. ${ }^{53}$ Payments including a "TAXEIP" string are obvious stimulus disbursements, but such payments mainly hit cards later in 2020 in our data, and thus many payments especially those in April and May - had more generic Treasury-related deposit strings. We therefore further search for stimulus payments in our Treasury deposit categories that do not represent recurring payments such as SSA, SSI, and VA. In particular, we search for payments where the timing and amounts are consistent with the EIP1 payment schedule. ${ }^{54} \mathrm{We}$ observe a number of payments starting on April 10, 2020, that match the stimulus amounts, with most of these payments found within our "TAXREF" and "DIRDEP" categories. Figure A.4 shows the distribution of payment amounts that we identify as stimulus payments in April 2020 using this method.

\footnotetext{
${ }^{53}$ The US Treasury also sent out millions of EIP payments to taxpayers via prepaid debit cards. Many of these cards appear in the Facteus data with the electronic signature "ONE-TIME CONTRIBUTION FROM AFC ECONOMIC IMPACT PAYMENT." We place these cards in a separate category and do not use them in our analysis, since there is no information on spending behavior prior to the stimulus receipt, which is important for conditioning our analysis. We plan to explore the use of these cards further in future work.

${ }^{54}$ Given the noise infused by Facteus in the payment amounts, we allow for a band around the possible EIP1 benefit amounts of $\$ 1,200$ (single), $\$ 1,700$ (single plus one dependent), $\$ 2,200$ (single plus two dependents), and so on.
} 
Figure A.4. Distribution of EIP Transaction Amounts in "TAXREF" Category

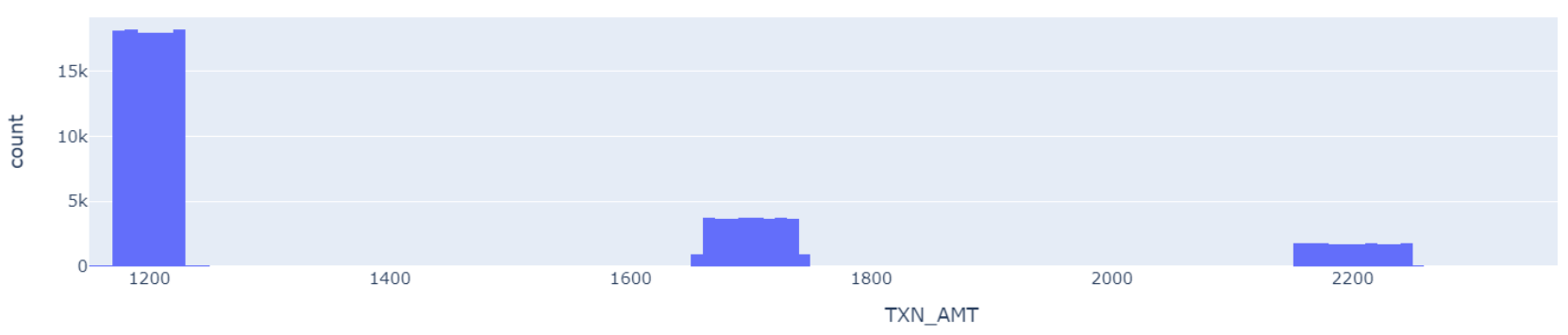

In addition, as a falsification test, we use our same approach but try to identify stimulus payments in April 2019, and we find none, which suggests our method captures actual stimulus payments when they occurred. Indeed, the deposit amounts from the Treasury in the "TAXREF" and "DIRDEP" categories in April 2019 are much more idiosyncratic, as one might expect for standard tax refunds and other forms of non-stimulus payments and reimbursements from the US government.

\section{Identifying Tax Refunds}

We identify federal tax refund payments after searching for all US Treasury payments and separating out the likely stimulus payments. In particular, we cluster transactions by MNME to obtain common patterns containing the generic substring "TAX[]+REF," which we do not identify as stimulus payments. Based on these patterns, we manually determine which ones are clearly from the US Treasury, which ones are state tax refund payments, and which ones are potentially ambiguous. In our analysis, we use only the transactions that are clearly tax refunds from the US Treasury. Additional details of our procedures for identifying stimulus payments and US Treasury payments more generally are available upon request.

\section{Cleaning Demographic Data}

\section{Location Data}

The Facteus data contain a field with information on the location (Zip code) where the cardholder resides (CRD_HLDR_ZIP). The field typically contains as many as nine digits along with spacing or dashes between the digits in some instances. In addition to various numbers of digits, some entries include letters, which typically are used in Canadian Zip 
codes. $^{55}$ We use a REGEX approach to clean these data and determine which cards have valid Zip code information. Invalid Zip codes are those for which the field is missing or null as well as those entries that do not meet our criteria for being a valid reported Zip code. In particular, a valid Zip code must match the REGEX:

- $[0-9]\{5\}([] *-?[] *[0-9]\{4\}) ? \$$,

which captures the Zip-plus-four format for the Zip code based on the following:

- The Zip code starts with five digits

- The five digits are optionally followed by a Zip code extension

- The extension can start with any number of spaces

- The spaces (if any) can be followed by a dash and any number of additional spaces

- The extension must have exactly four digits.

We also employ a slightly less stringent "LAX" valid Zip code criterion that, rather than requiring the Zip code extension to be exactly four digits, allows it to be from one to four digits.

Only cards with valid Zip code information meeting our LAX criterion are used in our analysis, since we condition our estimates on location-specific effects. For cards with more than one reported valid Zip code over time, we take the location that is reported most frequently. This approach ignores the fact that some cardholders may legitimately move over the course of our sample. At the same time, Facteus noted that different Zip code information for a given card could be due to reporting errors from Facteus' data providers. Therefore, taking the most frequently reported cardholder location seems like a reasonable (conservative) approach.

\section{Date of Birth Data}

Information on a cardholder's date of birth is also available in the Facteus data set. We construct a cardholder's age based on the reported year of birth. In instances where the DOB data changes over time for a cardholder, we take the most frequently observed birth year. As noted in the main text, these data are not used in our baseline estimates given that we have card-level fixed effects. We use the data though when we construct summary statistics for our sample and for some supplementary analysis.

\footnotetext{
${ }^{55}$ We drop these few cards from our analysis.
} 